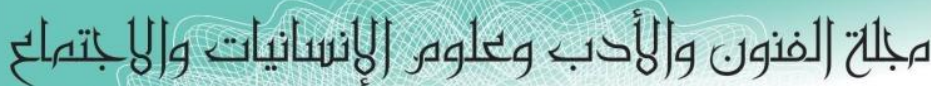

Journal of Arts, Literature, Humanities and Social Sciences

ISSN online: 2414 - 3383

ISSN print: 2616 - 3810

أيلول - لسبتمبر 2019

العدد (43)

\title{
قياس اتجاهات الأسرة السعودية نحو الاستهلاك الأكي
}

\author{
د. إنعام أحمد عابد شعيبي

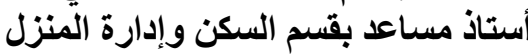

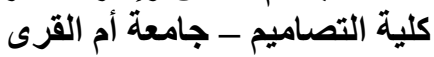 \\ المملكة العربية السعودية المية
}

الملخص

يعد تثكيل مو اقف واتجاهات المستهلك لتحديد خيار اته نحو صورة المنظمات أو علامنها التجارية غير قاصرة التهات

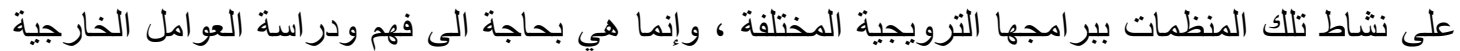
و التي تمثل الحر الك التفاعلي بين الأفراد وقدرة ذلك الحر الك على تشكيل اتجاهات إيجابية أو سلبية أو محايدة

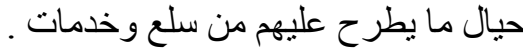

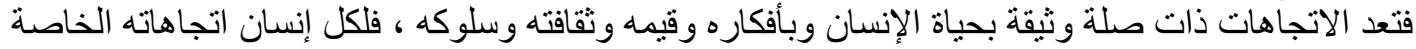

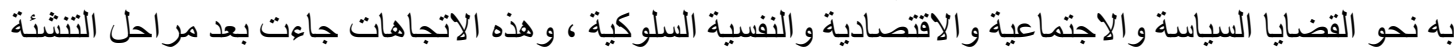

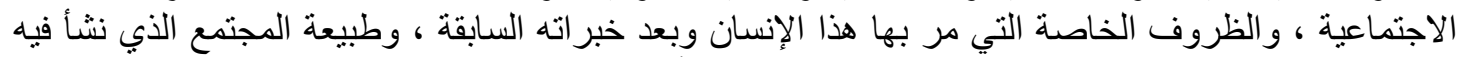

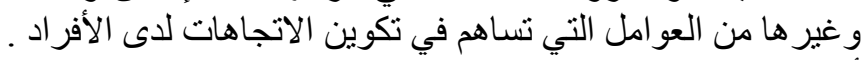

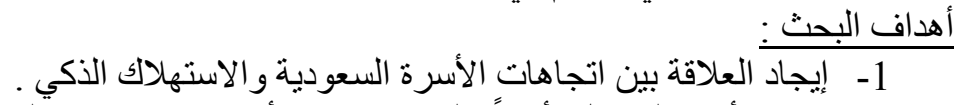

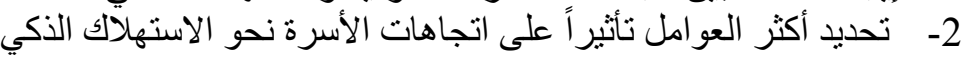

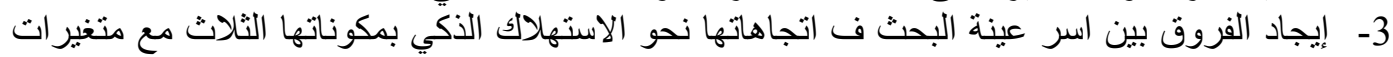

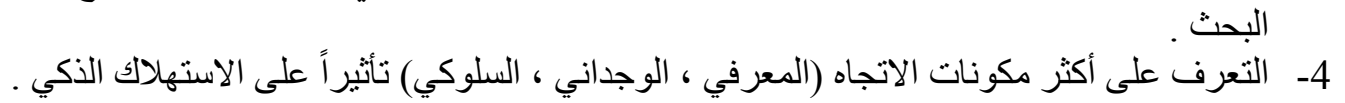

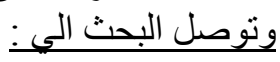
- - وجود فروق ذات دلاتلة إحصائية بين متوسط درجات أفراد العينة في الاتجاهات نحو الاستهلاك الذكي

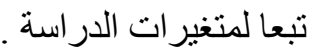

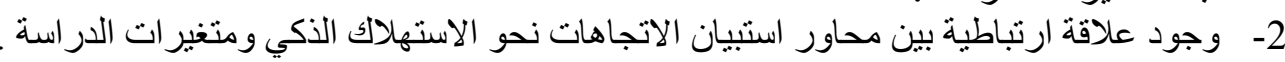

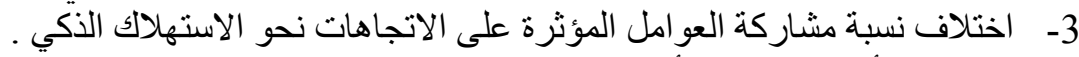

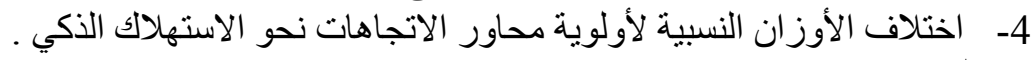
و أوصي البحث ثقافة الاستهلاك الذكي بين الأسر وزيادة و عبهم حول هذا الأمر ، مع مر اعاة استخدام لغة مبسطة

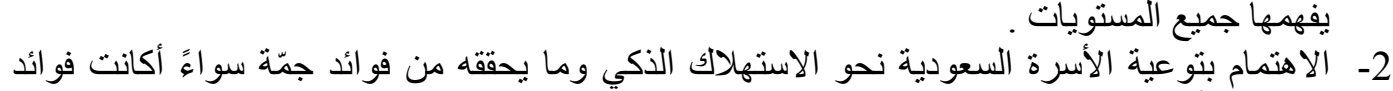

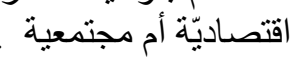

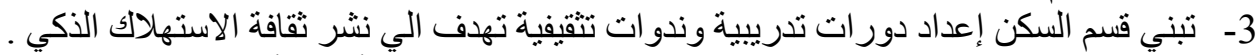

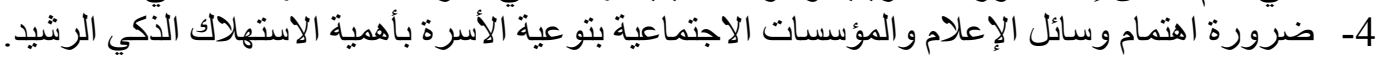




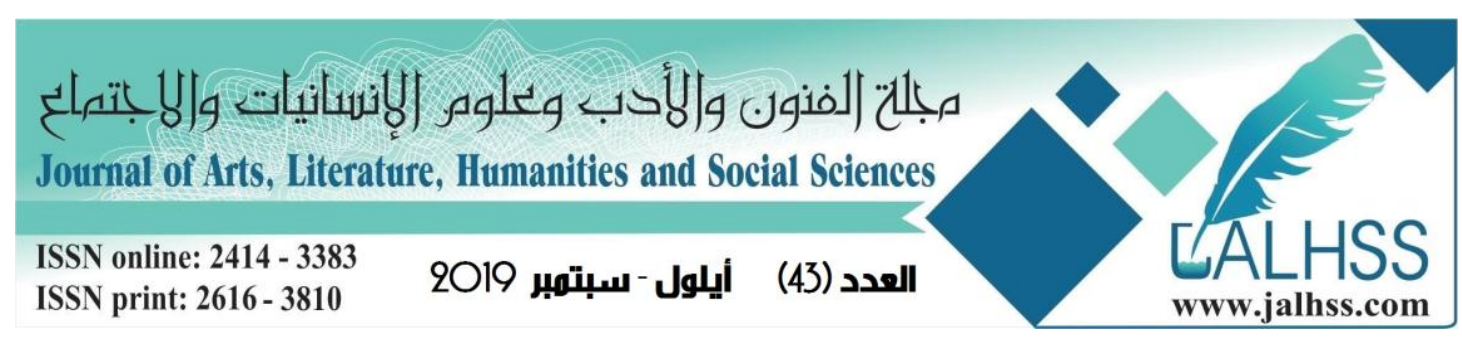

\title{
Measuring Saudi Family Trends towards Smart Consumption
}

\begin{abstract}
The formation of consumer attitudes and attitudes to determine their choices towards the image or brand of organizations is not limited to the activity of these organizations with different promotional programs, but they need to understand and study the external factors that represent the interactive movement between individuals and the ability of that movement to form positive, negative or neutral trends about what They are offered goods and services.

Trends are closely related to human life, ideas, values, culture and behavior. Each person has his own attitudes towards political, social, economic and psychological behavioral issues. These trends came after the stages of socialization, the special circumstances experienced by this person and after his previous experiences, the nature of the society in which he grew up, etc. Factors that contribute to the formation of trends in individuals.

research aims :

1- Finding the relationship between Saudi family trends and smart consumption.

2. Determine the most influential factors on family attitudes towards smart consumption.

3 - Find the differences between the families of the research sample in their attitudes towards smart consumption with its three components with the research variables.

4 - Identify the most components of the trend (cognitive, emotional, behavioral) impact on smart consumption.

The research concluded:

1- There are statistically significant differences between the average scores of the sample in the attitudes towards smart consumption according to the study variables.

2 - There is a correlation between the axes of the questionnaire trends towards smart consumption and study variables.

3 - Different participation rate factors affecting trends in smart consumption.

4- Different relative weights of priority axes of trends towards smart consumption.

I recommend searching by:

1. Disseminate the culture of smart consumption among families and increase their awareness about this, taking into account the use of simplified language understood by all levels.

2 - Attention to raise the awareness of the Saudi family towards smart consumption and its benefits, whether economic or social benefits.

3 - Adopting the Department of Housing to prepare training courses and educational seminars aimed at spreading the culture of smart consumption.

4 - The need for media and social institutions to raise the awareness of the family of the importance of smart consumption rational.
\end{abstract}




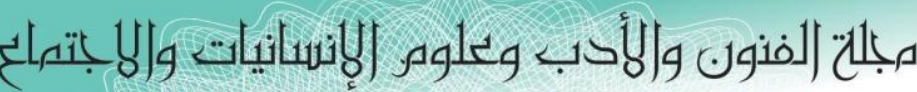

Journal of Arts, Literature, Humanities and Social Sciences

ISSN online: 2414 - 3383

ISSN print: 2616 - 3810

\section{العدد (43) ايلول - سبتهبر 2019}

يعد تشكيل مواقف واتجاهات المستهلك لتحديد خيار اته نحو صورة المنظمات أو علامتها التجارية غير

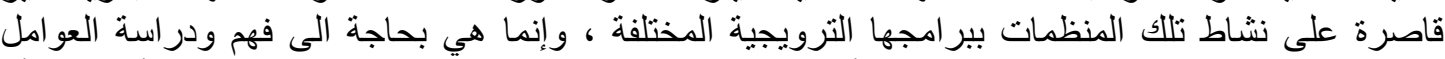

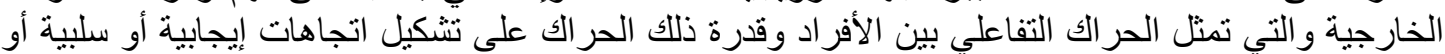

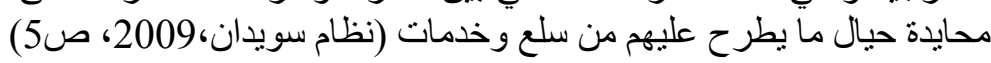

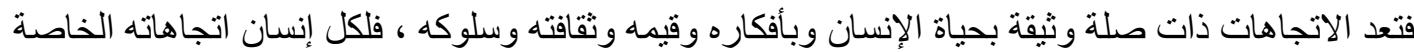

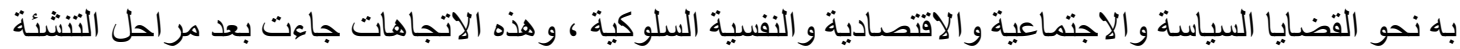

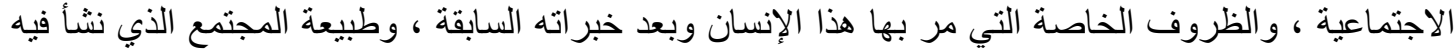

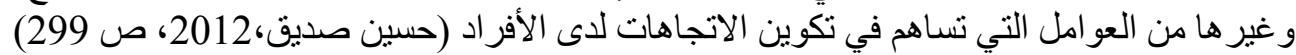
فالاتجاه عملية معرفية ذهنية معقدة تمثنل بالنزو ع و الميل الثنابت نسبيا نحو الأشياء و الأشخاص (محمد سلطان

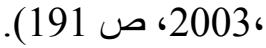

وتعتبر الأسرة من أهم العوامل المؤثرة في تكوين الاتجاهات وتتكيلها وتعزيز ها لاى أبنائها، فالأسرة هي

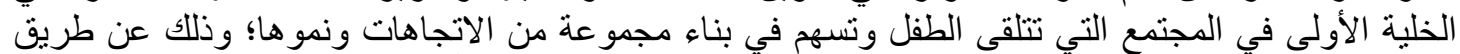

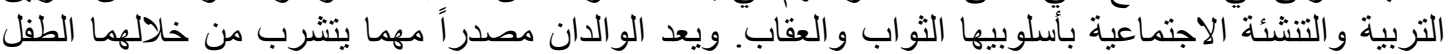

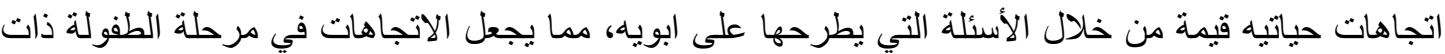

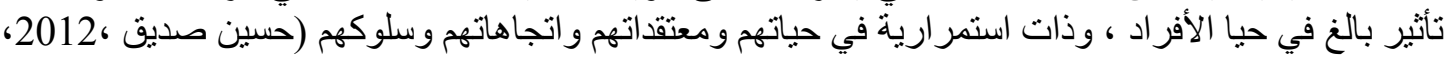

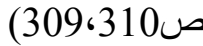

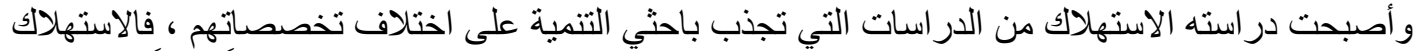

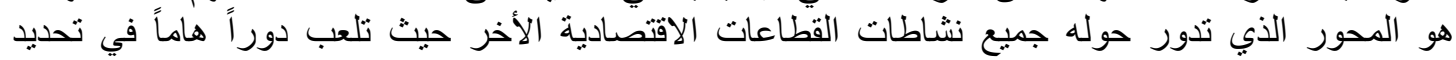

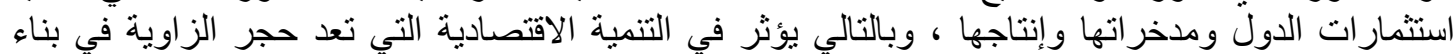

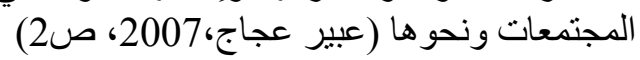

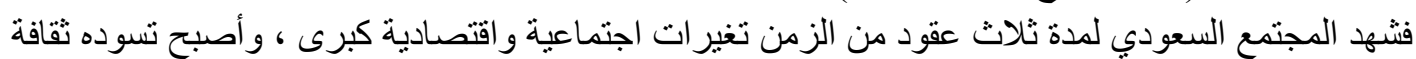

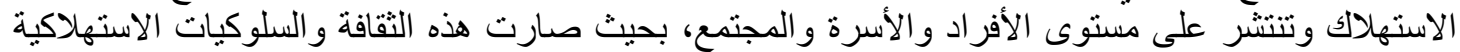

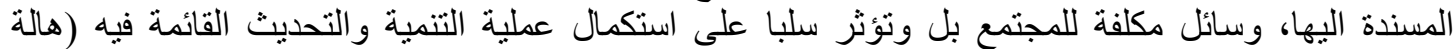

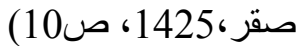

و هذا الأمر هو العامل المشترك بين الأسر في العصر الحالي أنها أصبحت اسر مستهركة مهما اختلفت مو اقعها

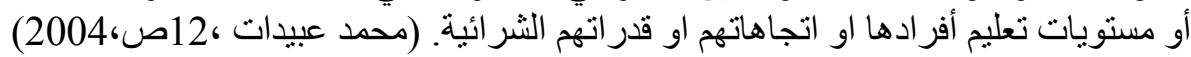

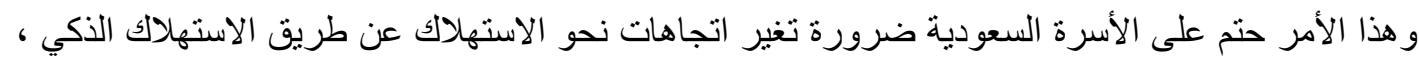

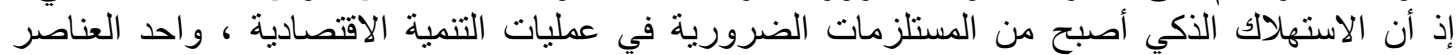

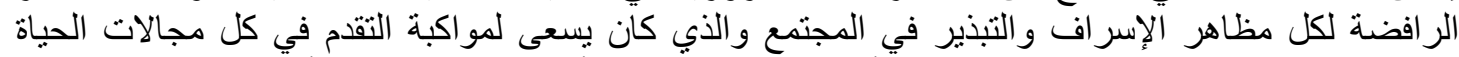

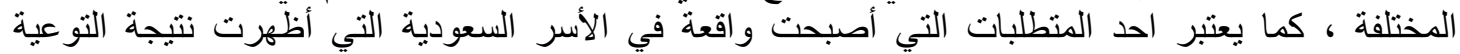

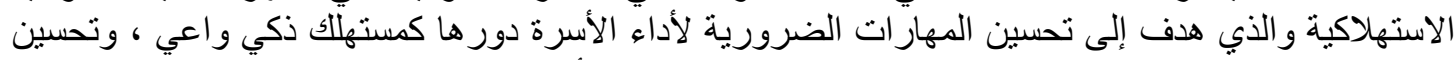

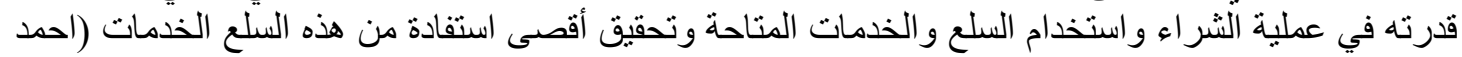

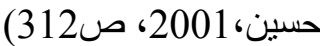

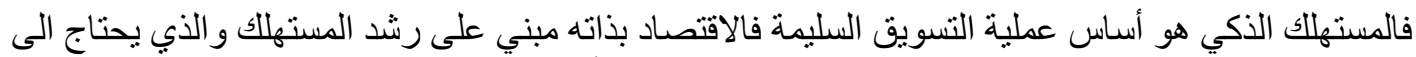
توفر المعلومة حول الخدمات والسلع واختيار التوفير هو الدذخل الأساسي للاستهلاك الذانكي.

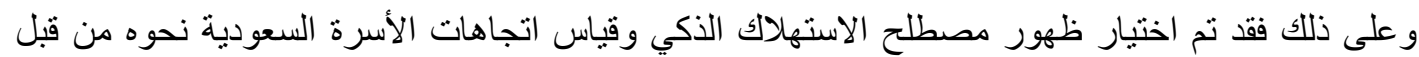

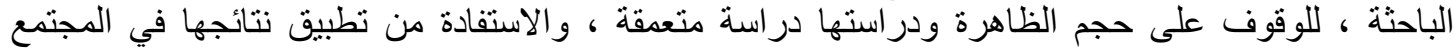

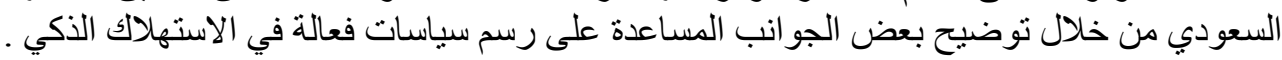

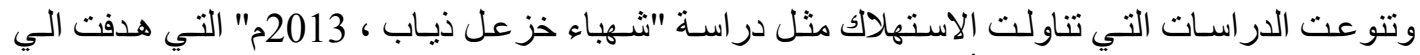

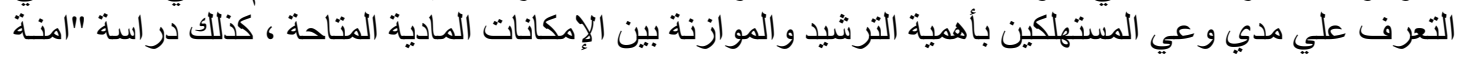




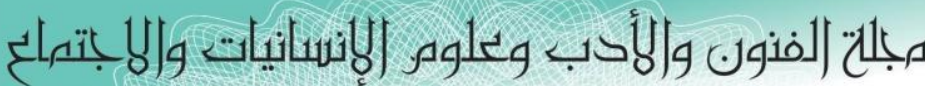

Journal of Arts, Literature, Humanities and Social Sciences

ISSN online: 2414 - 3383

ISSN print: 2616 - 3810

\section{العدد (43) ايلول - سبتهبر 2019}

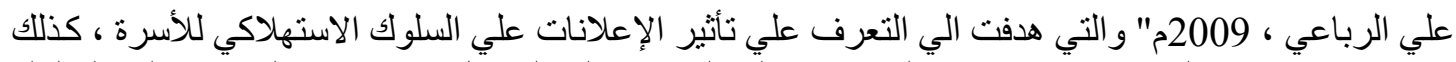

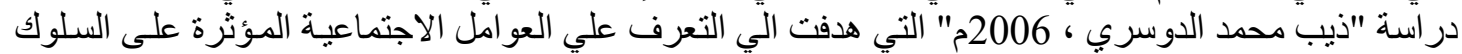

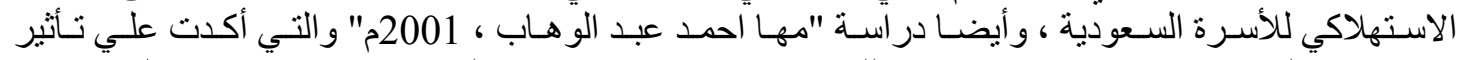

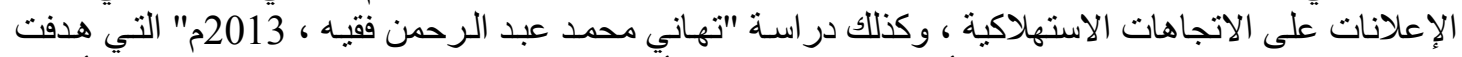

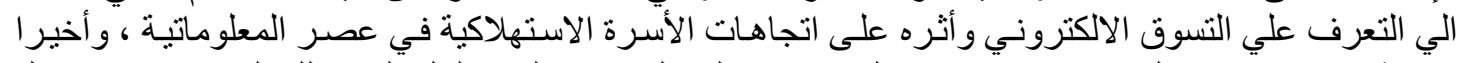

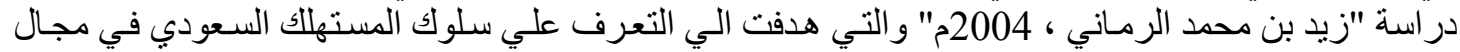

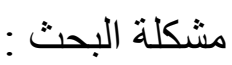

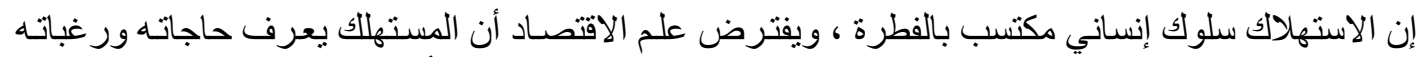

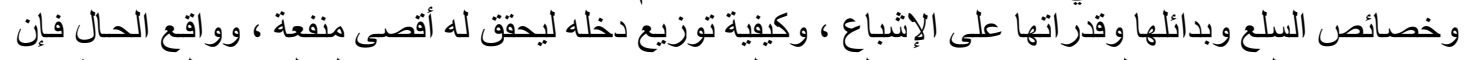

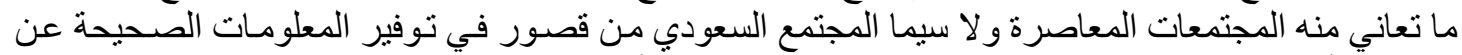

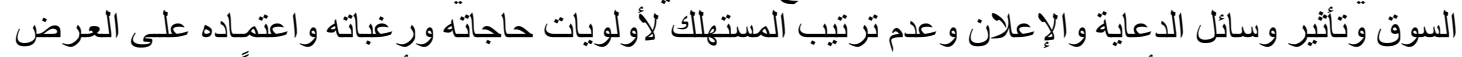

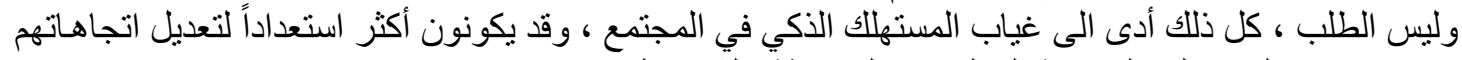

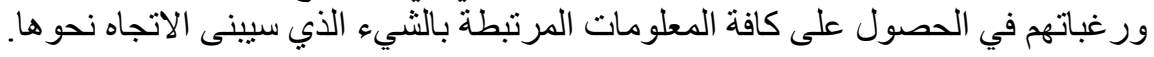

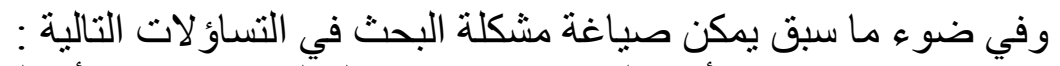

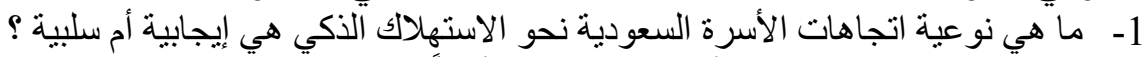

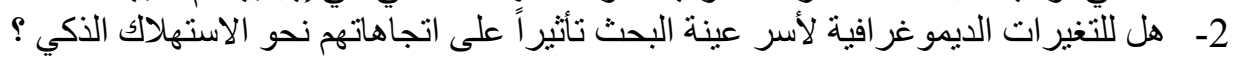

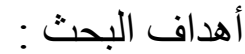

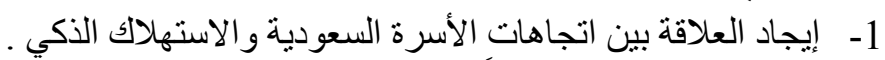

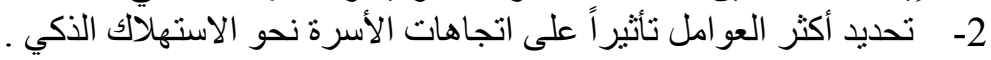

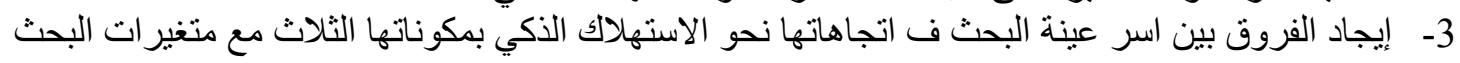
4- التعرف على أكثر مكونات الاتجاه (المعرفي ، الوجداني ، السلوكي) تأثير اً على الاستهلاك الذكي .

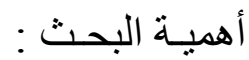

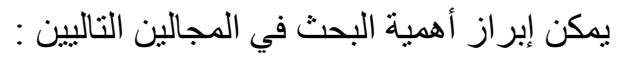

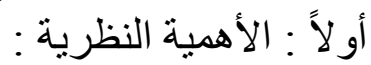

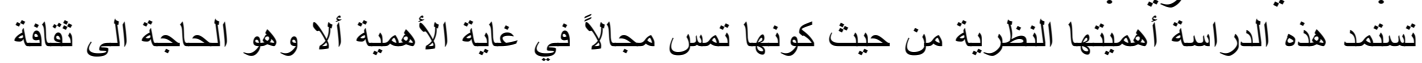

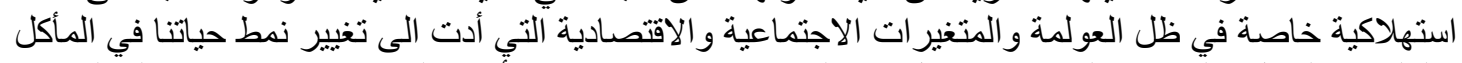

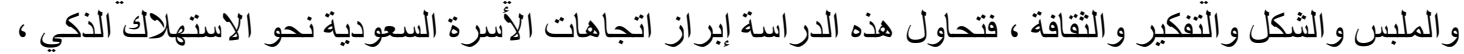

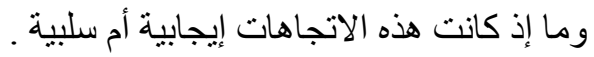

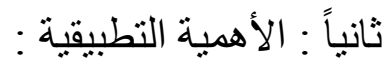

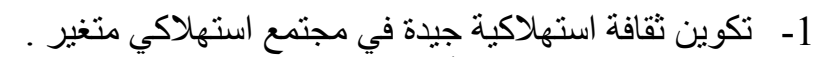

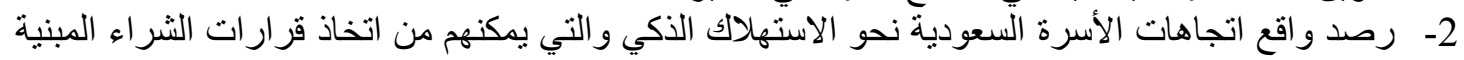
على خلفية علمية صحيحة .

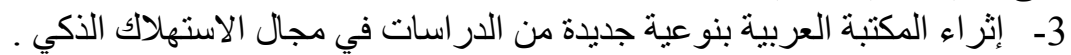

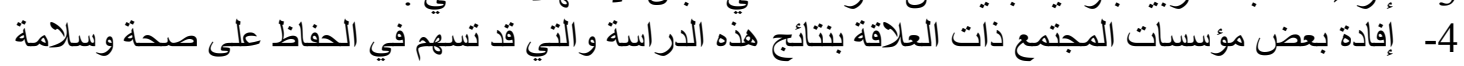
المستهلك وترشيده .

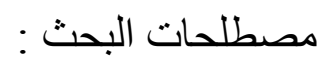

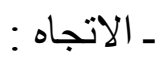
- ميل الفرد نحو اتخاذ موقف معين او تبني فكرة ما في صورة تفضيل أو عدم تفضيل (طارق طه، ص2006،265 


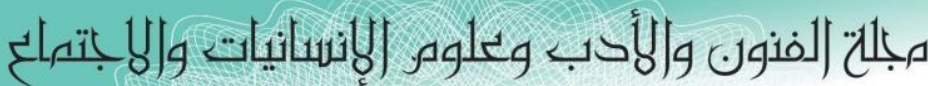

Journal of Arts, Literature, Humanities and Social Sciences

ISSN online: 2414 - 3383

ISSN print: 2616 - 3810

\section{العدد (43) ايلول - سبتهبر 2019}

- نوع من استجابات الفرد إزاء موضوع أو فكرة معينة وقد تكون هذه الاستجابات إيجابية أو سلبية من خلال

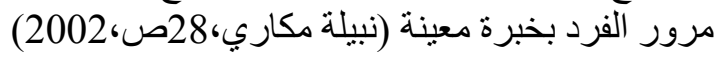
ـ ت تعرفه الباحثة إجر ائيا :

- مثاعر داخلية لاى الأفراد ، فهي مكونات نفسية وعقلية سلبية كانت أو إيجابية تتكون لدى الفرد نتيجة ما

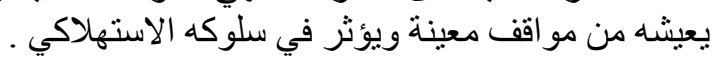

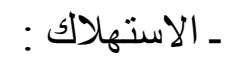

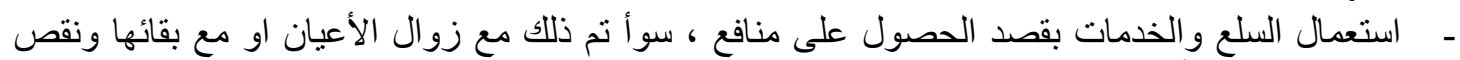

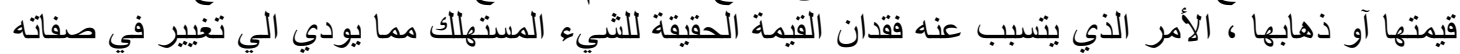

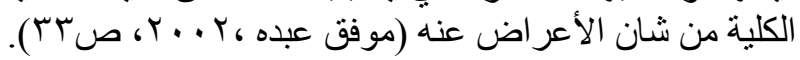

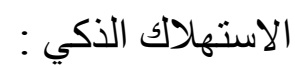
- استخدام الموارد المتاحة بأفضل طريقة ممكنة و إيجاد البدائل ذات الجودة العالية بقدر الإمكان .

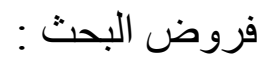
1- توجد فروق ذات دلالة إحصائية بين منوسط درجات أفراد العينة في الاتجاهات نحو الاستهلاك الذكي تبعا

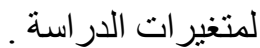
2- توجد علاقة ارتباطية بين محاور استبيان الاتجاهات نحو الاستهلاك الذكي ومتغير ات الدراسة .

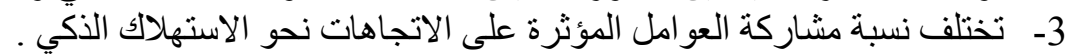

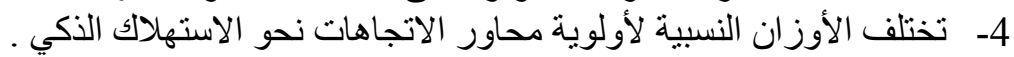

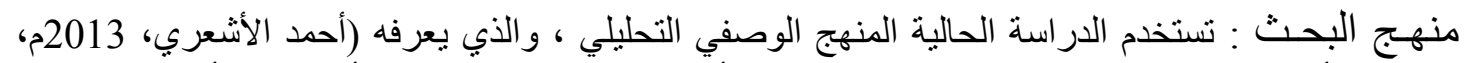

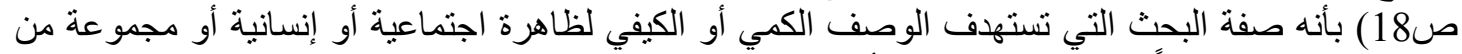

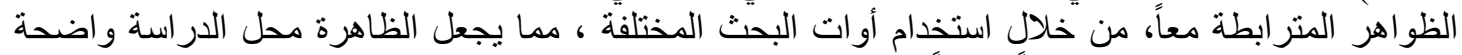

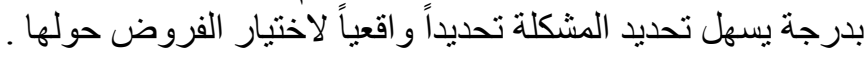

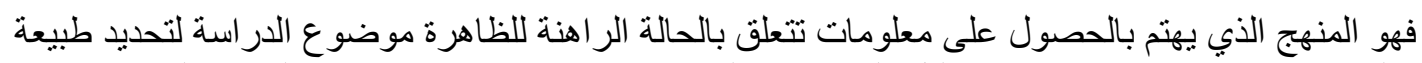

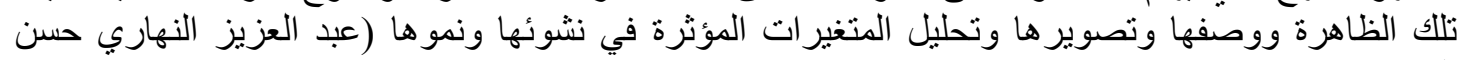

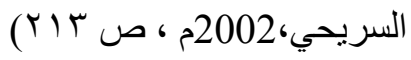

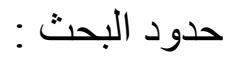

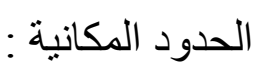

بناء على مشكلة البحث و أهدافه فقد طُبقت الدراسة الميدانية على مجمو عة من الأسر السعودية ، وذلك بغرض

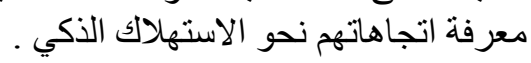

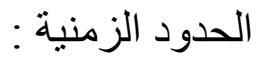

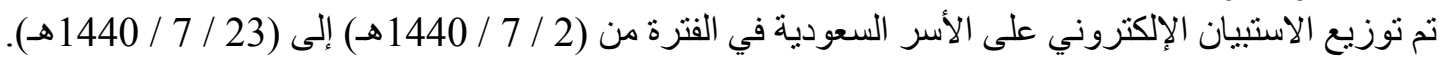

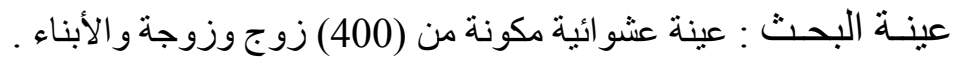
أدوات البحـث: : البحث: :

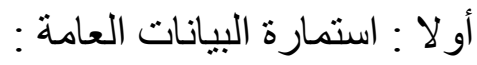

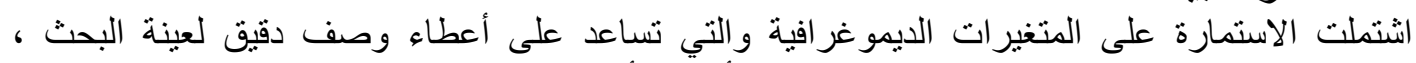

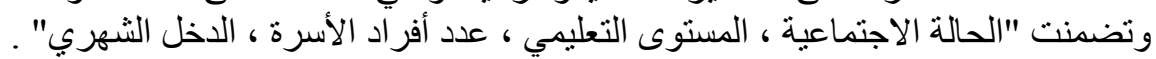

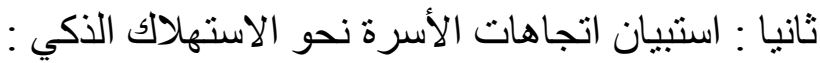

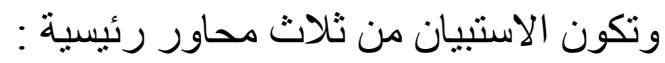

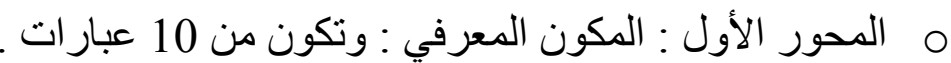
o المحور الثاني : المكون السلوكي : وتنكون من 10 : عبار عن عات . 


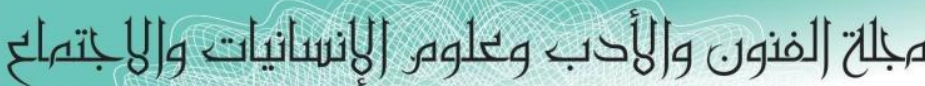

Journal of Arts, Literature, Humanities and Social Sciences

ISSN online: 2414 - 3383

ISSN print: 2616 - 3810

\section{العدد (43) ايلول - سبتمبر 2019}

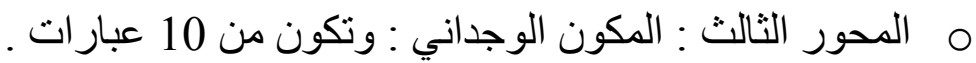

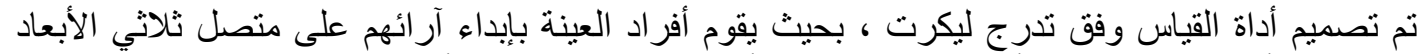

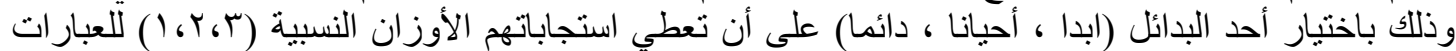

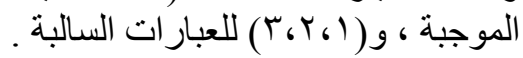

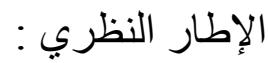

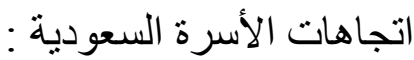

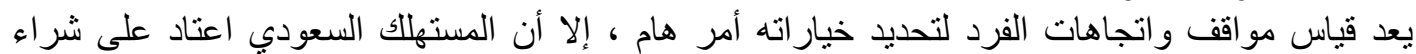

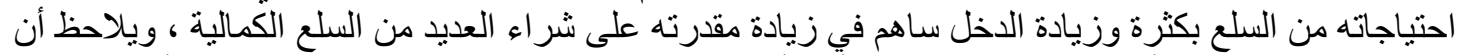

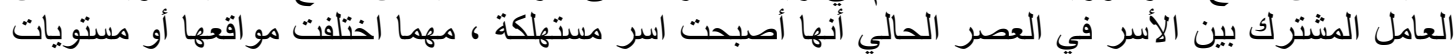
تعليم أفرادها أو اتجاهاتهم أو قدر اتهم الثر ائية .

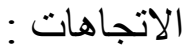

تعرف (نبيلة مكاري ،2002، ص 228) الاتجاهات بأنها نوع من استجابات الفرد إزاء موضوع أو فكرة

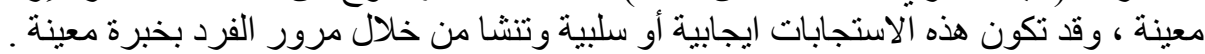

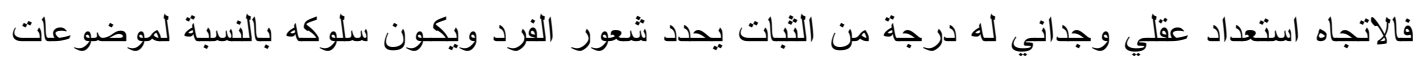

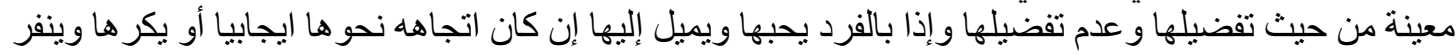

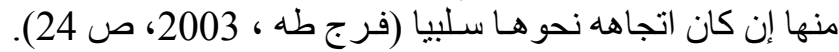

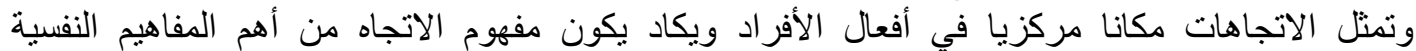

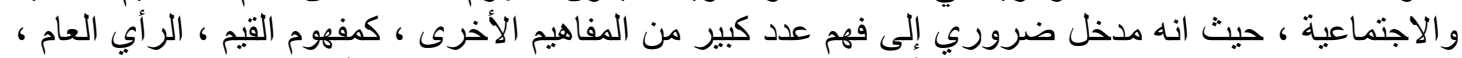

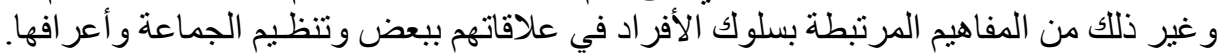

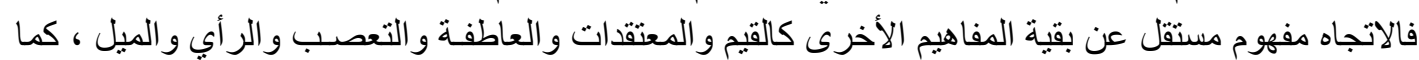

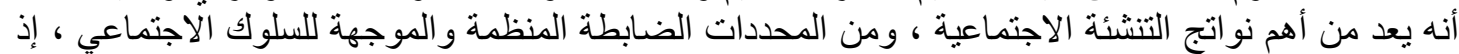

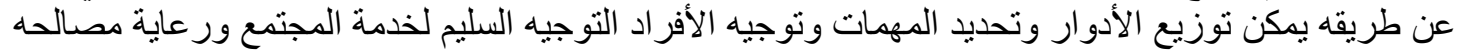

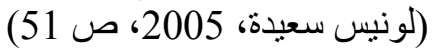
فالاتجاهات تعبير عن الششـاعر الداخلية لدى الأفراد و التي تعكس أو تكثف إذا ما كان لديهم ميول ايجابية أو

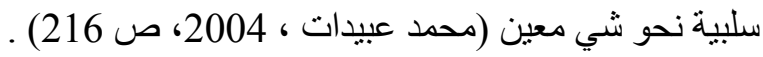

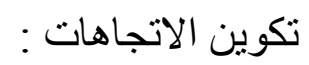

تتكون الاتجاهات نتيجة لتعرض الفرد لمنبهات ومثيرات في البيئة الخارجية تؤثر عليه من خلال عملية

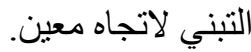

وذكر محمود العمبان (2010، ص 90 ، و 91 91) أن هناك مجمو عة من الأمور الهامة التي تؤدي إلى تشكيل وتكوين الاتجاهات لدى الأفراد و هي :

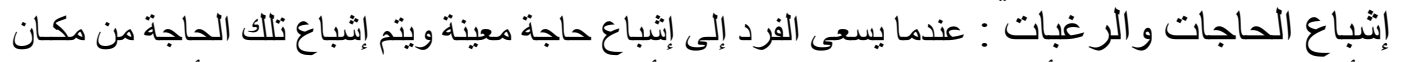

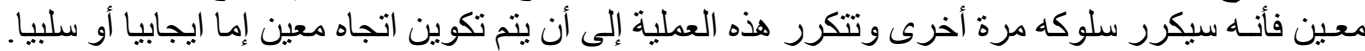

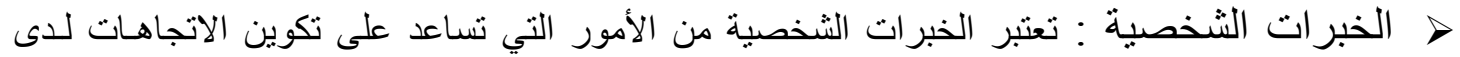

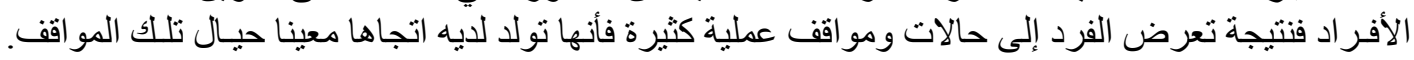

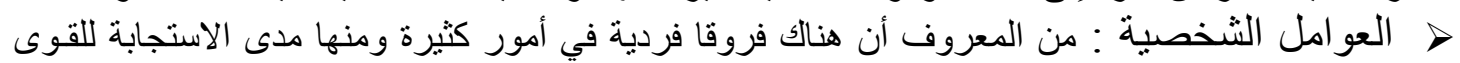

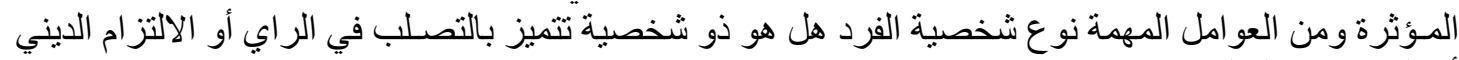

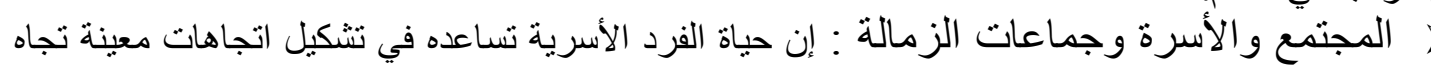

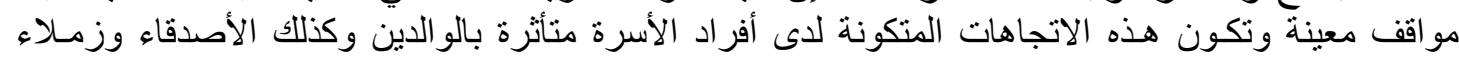




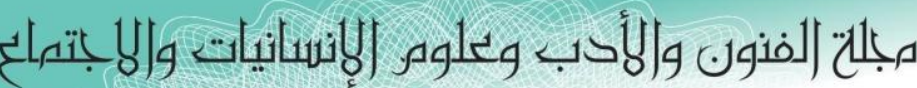

Journal of Arts, Literature, Humanities and Social Sciences

ISSN online: 2414 - 3383

ISSN print: 2616 - 3810

\section{أيلول -سبتهبر 2019}

العدد (43)

العمل كلهم يؤثرون في تكوين الاتجاهات من خلال اعتناق الأفر اد للقيم ومبادئ الجماعة حتى يكونوا مقبولين

فيها.

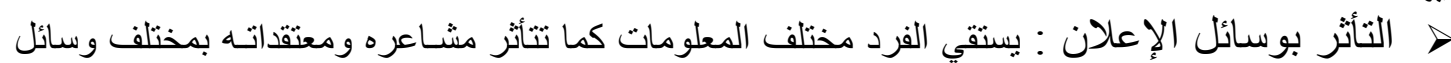

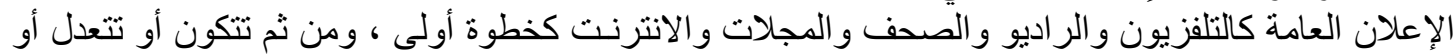

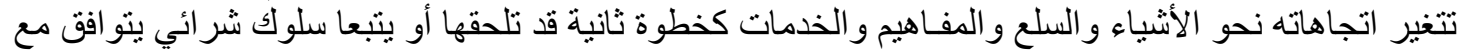

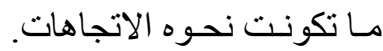

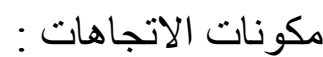

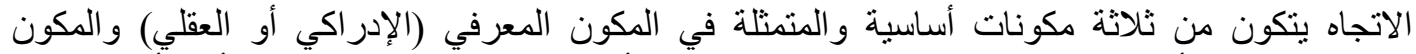

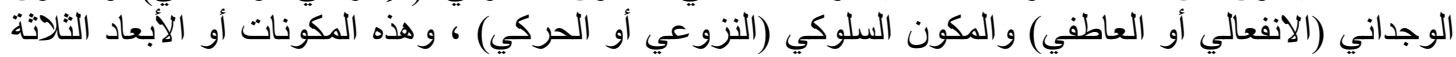

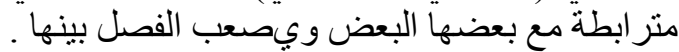

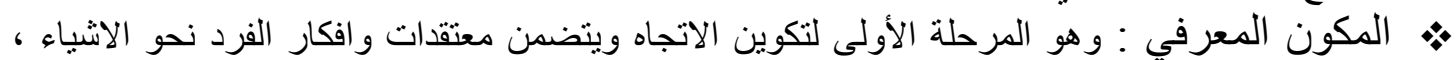

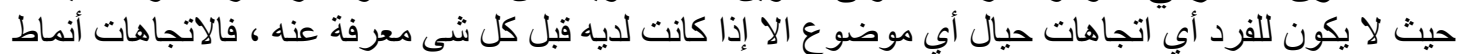

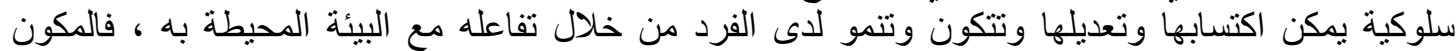

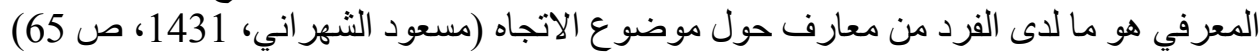

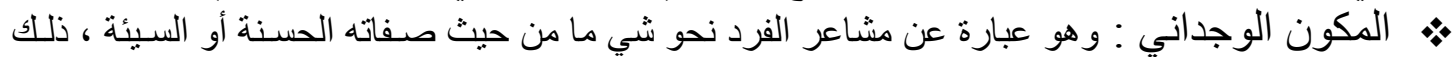

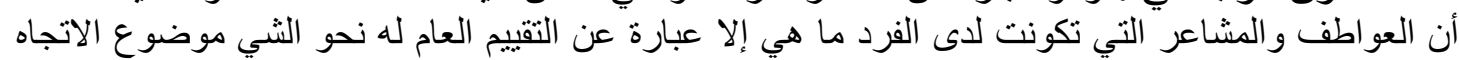

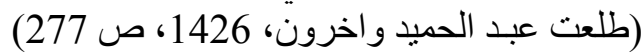

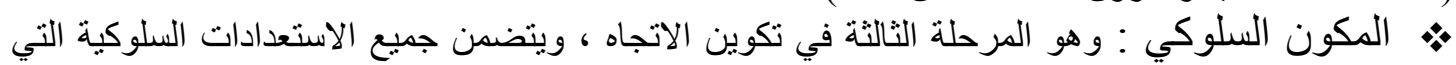

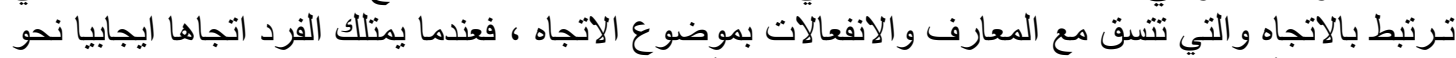

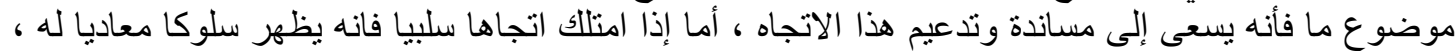

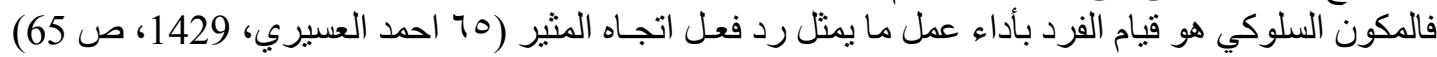

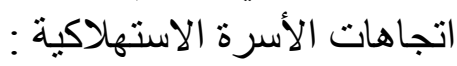

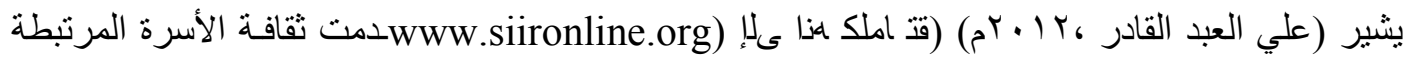

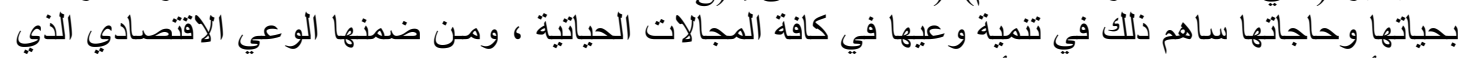

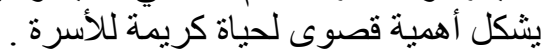
فكلما ارتقى الوعي كانت الأسرة أكبر قدرة على التصرف المالي المتوازن بين الاستهلاك والاستثمار

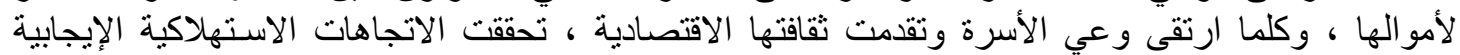

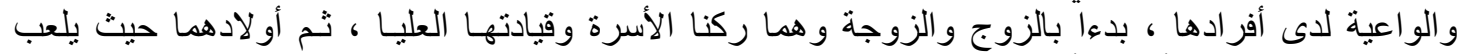

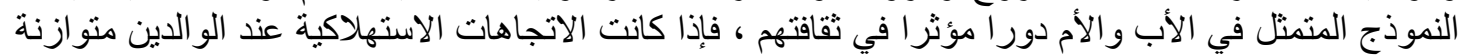

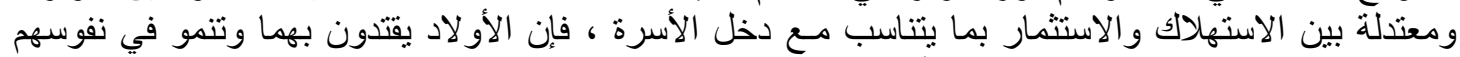

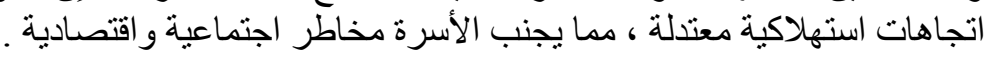

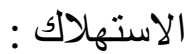

يمكن النظر الي الاستهلاك على انه الهلف او الغاية الأساسية لكل النشاطات الاقتصادية ، كما انه أحد

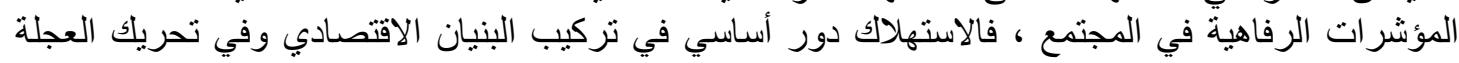
الاقتصادية.

ويعرف الاستهلاك لغة في قاموس المعاني (www.almaany.com) بانه استهلاك (هـ لـ ك) (مصدر استهلاك) و(اصطلاحاً) استخذام سلعه أو خدمة في تحقيق منفعة بصوره مباشره بدون استعمالها في إنتاج سلعة

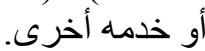

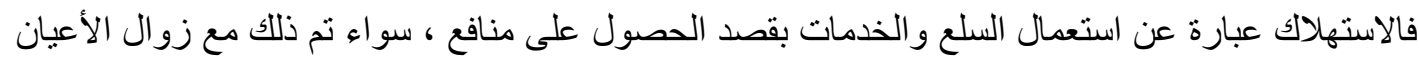

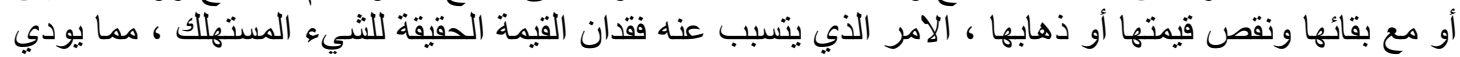

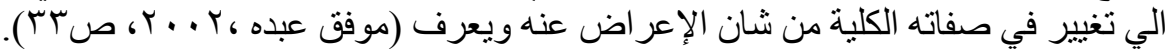




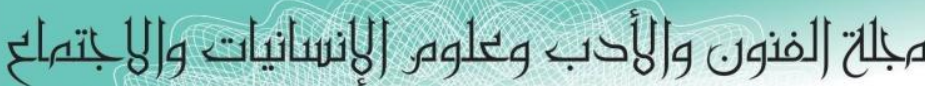

Journal of Arts, Literature, Humanities and Social Sciences

ISSN online: 2414 - 3383

ISSN print: 2616 - 3810

\section{العدد (43) ايلول - سبتهبر 2019}

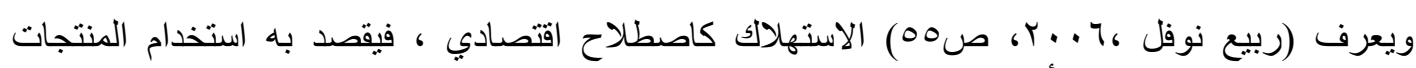

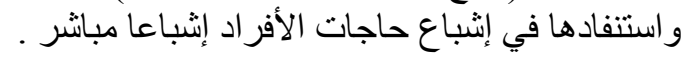

$$
\begin{aligned}
& \text { أنواع الاستهلاك : } \\
& \text { الاستهلاك الوسيط : }
\end{aligned}
$$

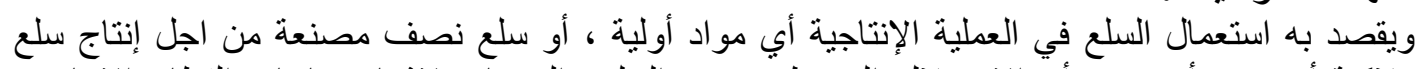

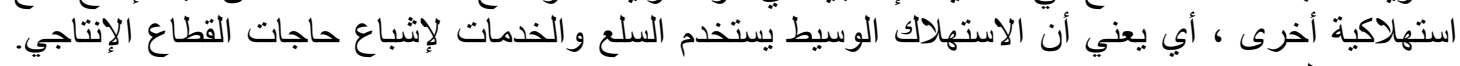

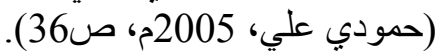

$$
\begin{aligned}
& \text { الاستهالك النهائي : }
\end{aligned}
$$

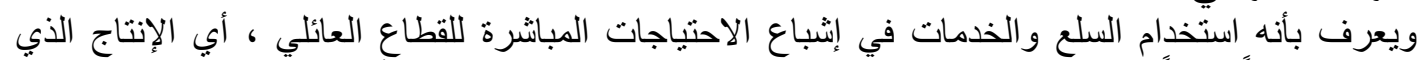

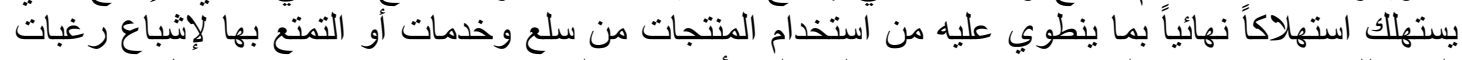

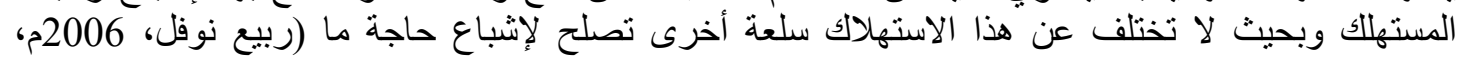

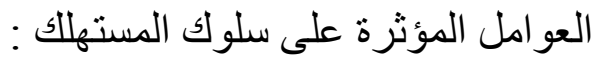

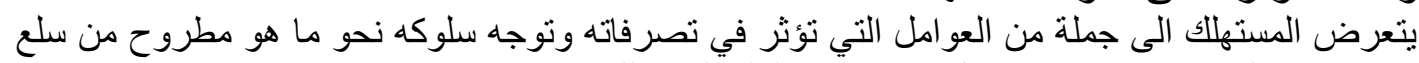

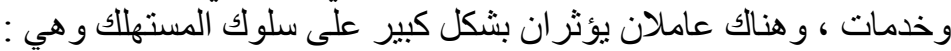

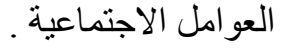

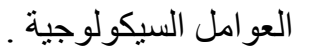

$$
\begin{aligned}
& \text { أولا : العوامل الاجتماعية : } \\
& \text { وتشتمل على خمس عو امل : }
\end{aligned}
$$

الثقافة :

تعتبر الثقافة عامل حاسم وأساسي في قرار الفرد لحاجاته ورغباته لأنها تنبع أصلا من القيم و المعتقدات

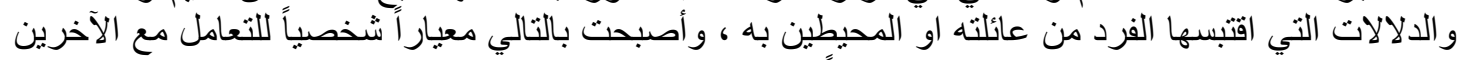

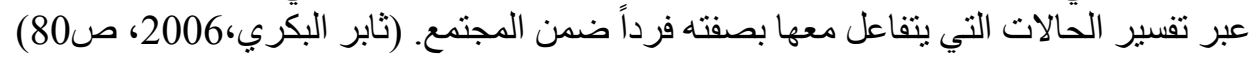

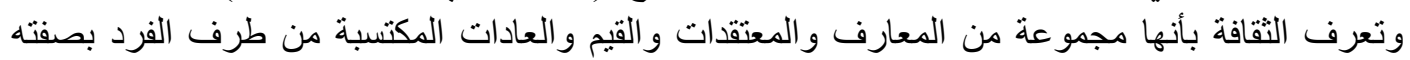

ينتمي الى مجتمع معين (Denis Darby, 2003).

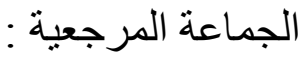

تعرف جماعات المرجعية بأنها تلك المجموعات التهات البشرية التي يمكن ان تستخدم كإطار مرجعي للأفراد في

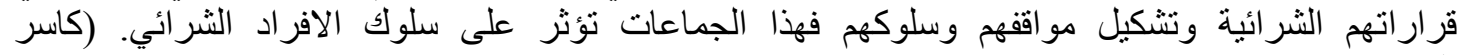

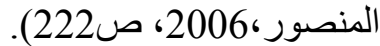

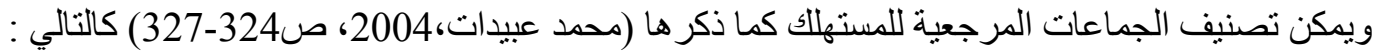

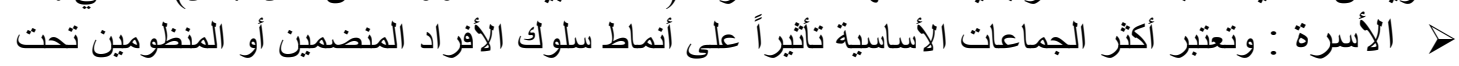
> لو الأصأُ الصدقاء : وهم عمليا جماعة غير رسمية لأنها عادة ما تكون غير منظمة وليس لديها فعليا أي سلطات

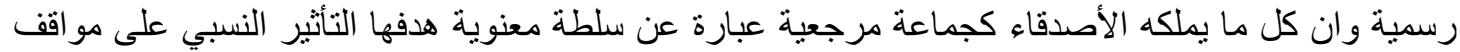

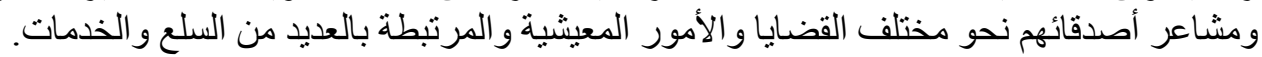

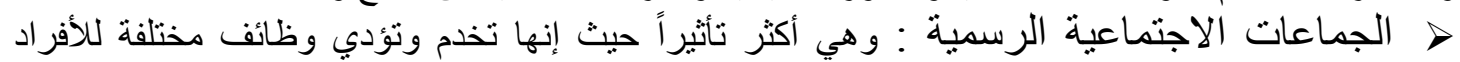

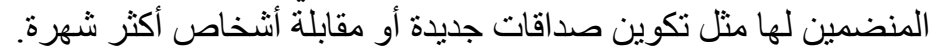

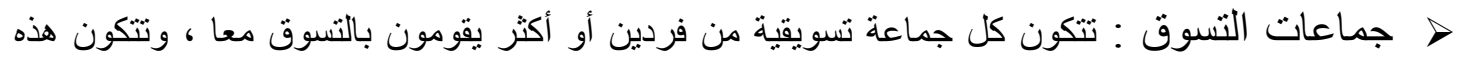

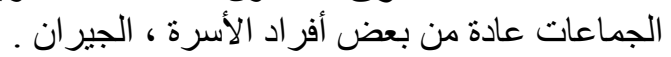




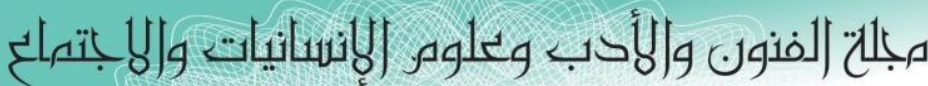

Journal of Arts, Literature, Humanities and Social Sciences

ISSN online: 2414 - 3383

ISSN print: 2616 - 3810

\section{العدد (43) ايلول - سبتهبر 2019}

> زملاء العمل : يعتبر زملاء العمل من الجماعات المرجعية الرسمية حيث يؤثر الأفراد وخاصة قادة الر أي

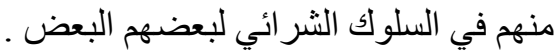

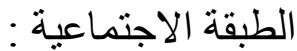

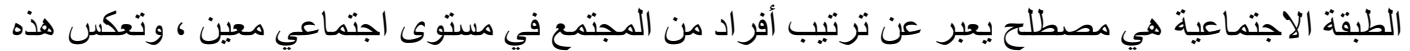

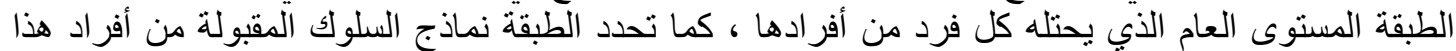

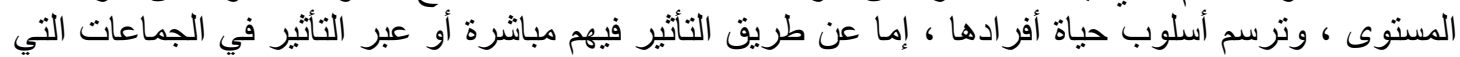

ينتمون إليها.

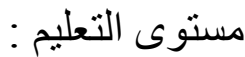

يعتبر التعليم عاملاً من أبرز العو امل التي تؤثر في سلوك الفرد ومدركاته ودو افعها ، بحيث يوسع التعليم أفق

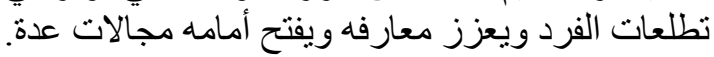

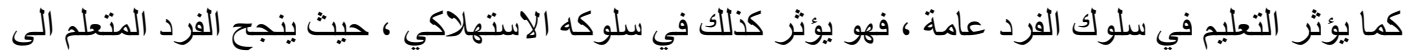

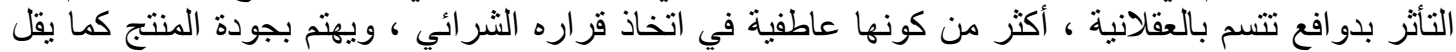

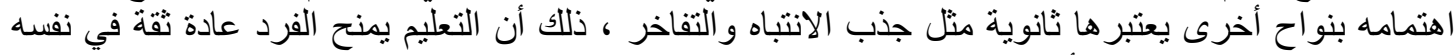

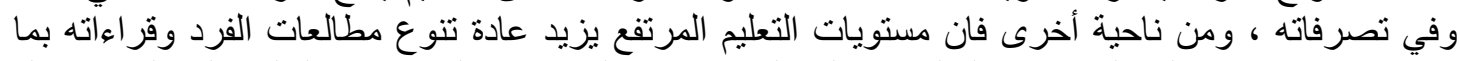

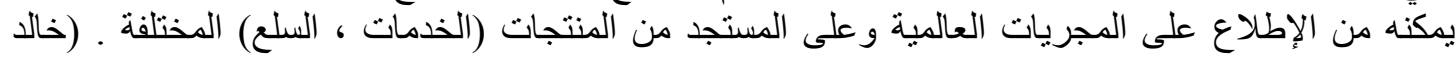

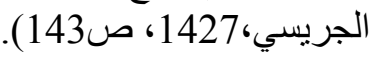

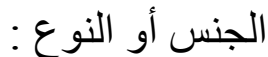

يتباين السلوك الإنساني تباينا كبير ا باختلاف نوع الفرد ، حيث يظهر فرق كبير بين سلوك المرأة وسلوك

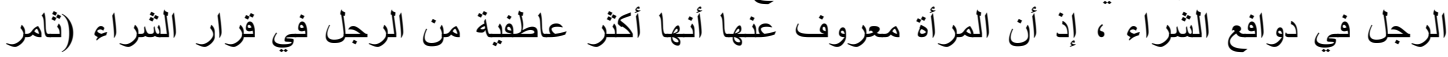

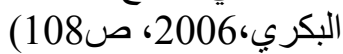
ثانياً : العو امل السيكولوجية "نفسية" :

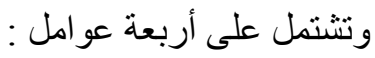

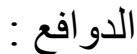

الدوافع هي قوى محركة تتمثل في الرغبات والحاجات التي يريد الإنسان إثباعها ، أو الأمور التي يريد

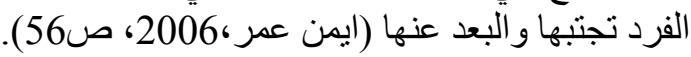

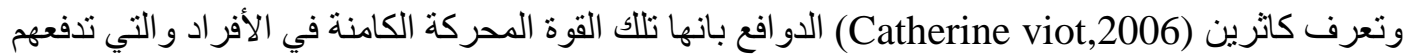

للسلوك باتجاه معين وتمكنهم من التعرف على البيئة وتفسير المعلومات المناتيات المتلقة بهذه البيئة .

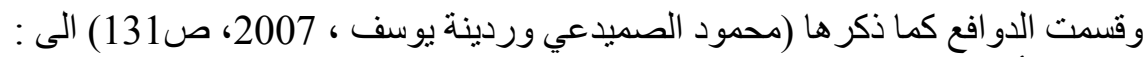

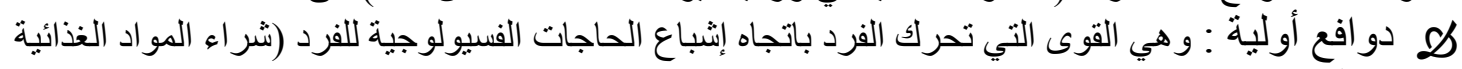

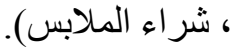
لهو دو افع ثانوية : هي القوى التي تحرك الفرد باتجاه إثباع حاجات تحقيق الأمان ، الحاجات الاجتماعية ،

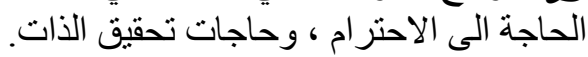

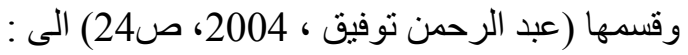

له دو افع عقلية : وتظهر في حالة ما إذا تم اتخاذ قرار الثراء بعد دراسة وتخطيط مسبق فيعتبر الثراء كو دو افع عاطفية : وتظهر في حالة ما إذا نم اتخاذ قرار الثراء بدون دراسة أو تخطيط مسبق فيعتبر دافع عاطفي. 


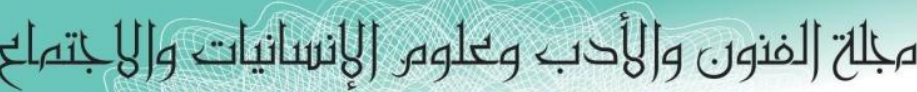

Journal of Arts, Literature, Humanities and Social Sciences

ISSN online: 2414 - 3383

ISSN print: 2616 - 3810

\section{العدد (43) ايلول - سبتمبر 2019}

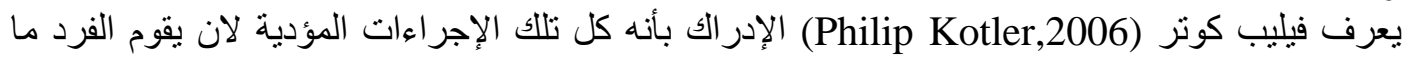

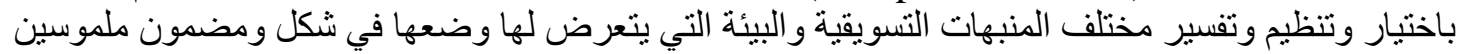

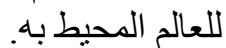

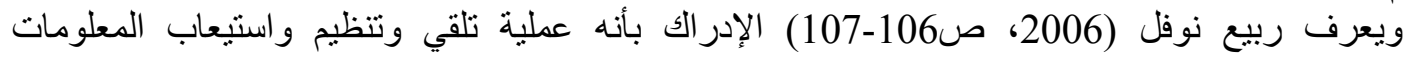

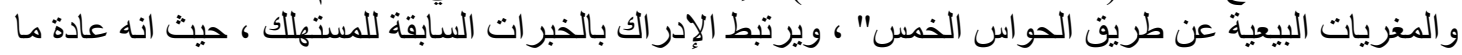

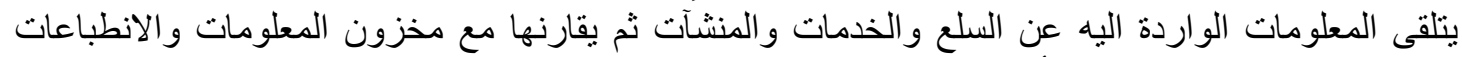

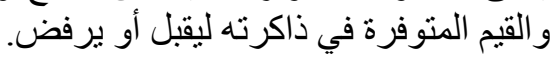

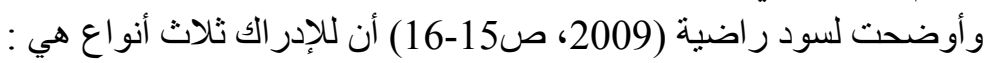

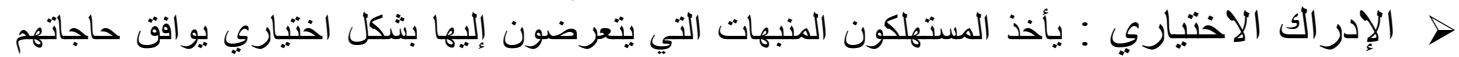

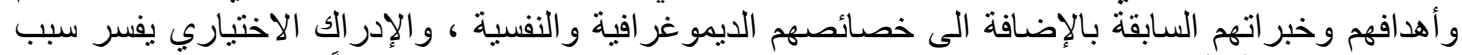

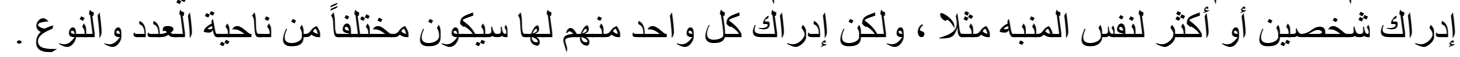

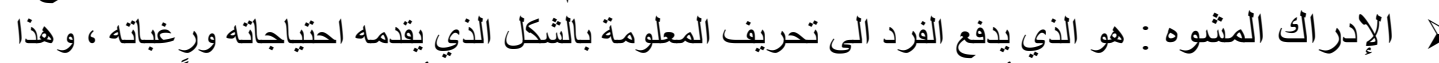

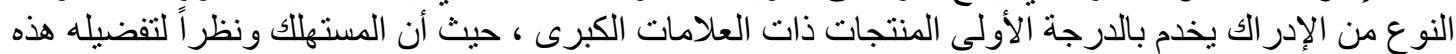

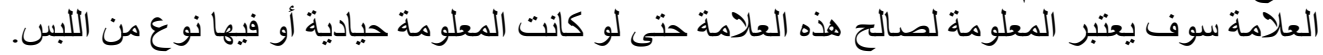

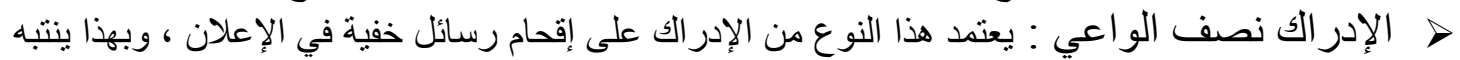

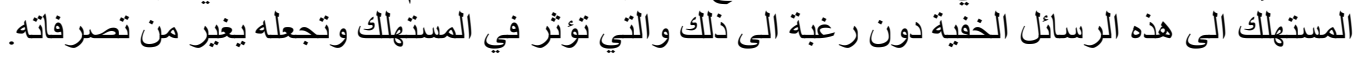

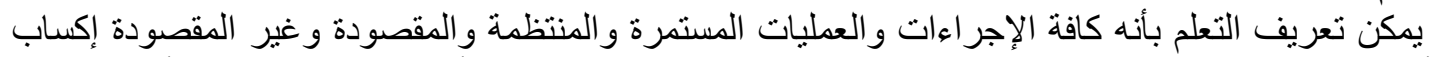

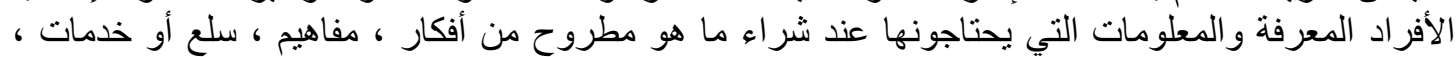

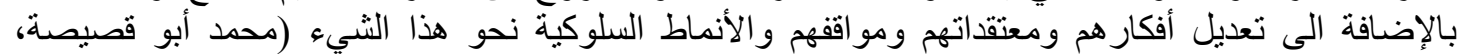

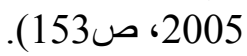

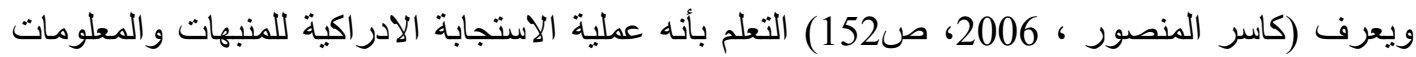

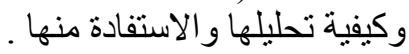

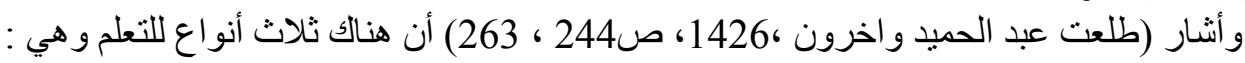

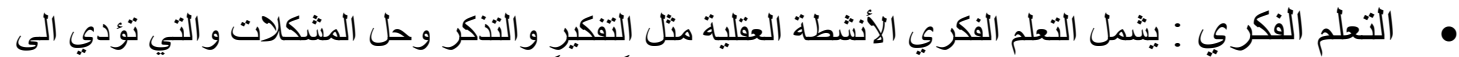

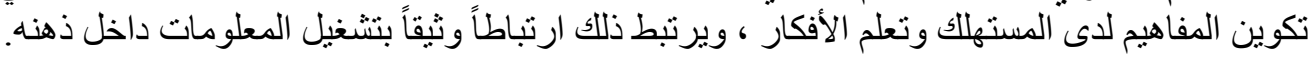

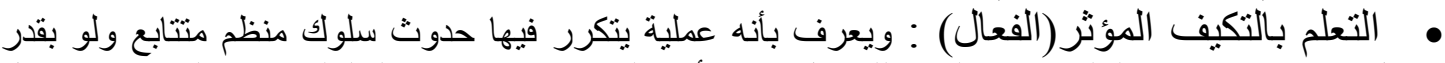

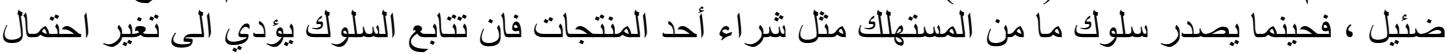

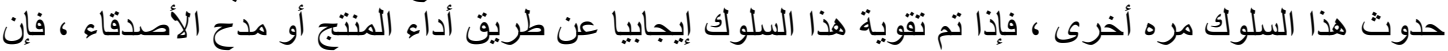

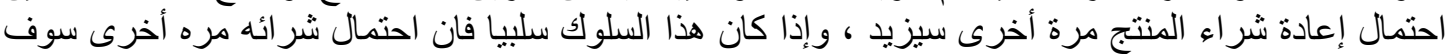
• التعلم بالتكيف التقليدي : الذي يضغط على التفاعلات الإيجابية من المستهلكين وهدفهم في ذلك ربط منتجاتهم بالمؤثر ات الإيجابية حتى تحدث عملية الثراء.

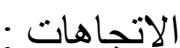

تمثل الاتجاهات مكانا مركزيا في أفعال الافراد ويكاد يكون مفهوم الاتجاه من أهم المفاهيم النفسية

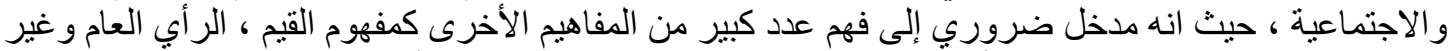
ذلك من المفاهيم المرتبطة بسلوك الأفر أد في علاقاتهم ببعض وتئر وتنظيم الجماعة وأعر افها.

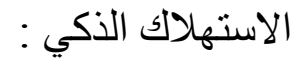
هو استخدام المؤارد المتاحة بأفضل طريقة ممكنة و إيجاد البدائل ذات الجودة العالية بقدر الإمكان. 


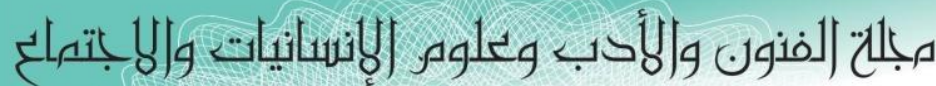
Journal of Arts, Literature, Humanities and Social Sciences

ISSN online: 2414 - 3383

ISSN print: 2616 - 3810

\section{العدد (43) أيلول - سبتمبر 2019}

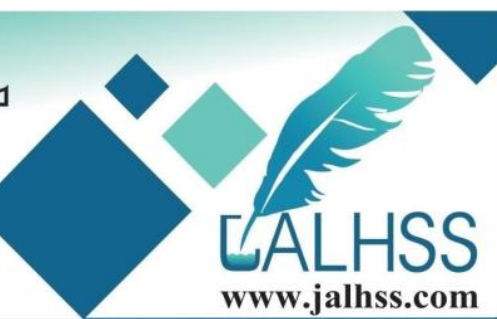

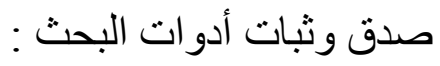

استبيان اتجاهات الأسرة نحو الاستهلاك الألكي :

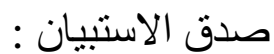

يقصد به قدرة الاستبيان على قياس ما وضع لقياسه.

الصدق باستخدام الاتساق الداخلي بين الدرجة الكلية لكل محور و والدانية الدارجة الكلية للاستبيان:

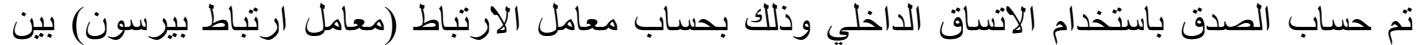

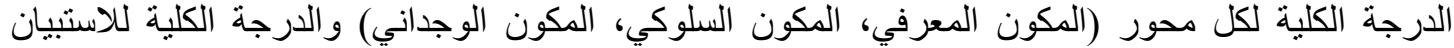

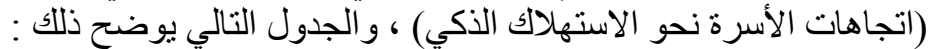
جدول (1) قيم معاملات الارتباط بين درجة كل محور ودرجة الاتنبيان اتجاهات الأسرة نحو الاستهلاك الذكى

\begin{tabular}{|c|c|c|}
\hline الدلالة - مالة & الارتباط & \\
\hline 0.01 & 0.871 & المحور الأول: المكون المعرفي \\
\hline 0.01 & 0.963 & المحور الثاني: الدكون السلوكي \\
\hline 0.01 & 0.755 & الدحور الثالث: المكون الوجداني \\
\hline
\end{tabular}

يتضح من الجدول أن معاملات الارتباط كلها دالة عند مستوى (0.01) لاقتر ابها من الو احد الصحيح مما يدل على صدق وتجانس محاور الاستبيان.

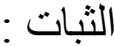

يقصد بالثبات reability دقة الاختبار في القياس و الملاحظة، و عدم تناقضه مع نفسه، و اتساقه واطر اده فيما

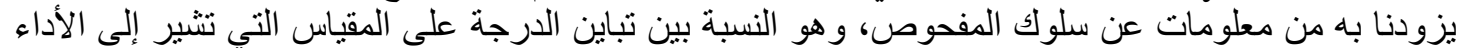

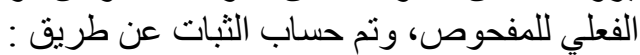

Alpha Cronbach 1

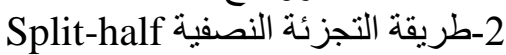

3uttman جيونمان

جدول (2) قيم معامل الثبات لمحاور استبيان اتجاهات الأسرة نحو الاستهلاك الذكي

\begin{tabular}{|c|c|c|c|}
\hline جيوتمان & التجزئة النصفية & معامل الفا & المحاور \\
\hline 0.874 & $0.926-0.858$ & 0.885 & المحور الأول: المكون المعرفي \\
\hline 0.751 & $0.802-0.731$ & 0.769 & المحور الثاني: المكون السلوكي \\
\hline 0.906 & $0.957-0.888$ & 0.917 & المحور الثالث: المكون الوجداني \\
\hline 0.813 & $0.860-0.793$ & 0.824 & ثبات استنيان اتجاهات الأسرة نحو الاستهلاك الذكي ككل \\
\hline
\end{tabular}

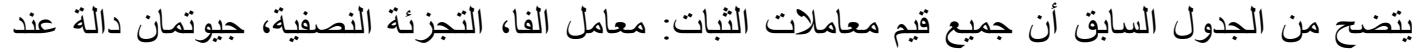
مستوى 0.01 مما يدل على ثبات الاستبيان .

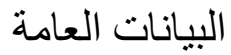
1-الجنس : جدول (3) توزيع أفر اد عبنة البحث تبعا لمتغير الجنس العنة

\begin{tabular}{|c|c|c|}
\hline النسبة\%\% & العدد & الجنس \\
\hline$\% 19$ & 76 & أب \\
\hline$\% 45.8$ & 183 & أم \\
\hline$\% 35.2$ & 141 & ابن / ابنة \\
\hline$\% 100$ & 400 & المجموع \\
\hline
\end{tabular}




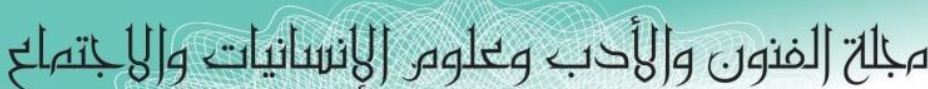

Journal of Arts, Literature, Humanities and Social Sciences

ISSN online: 2414 - 3383

ISSN print: 2616 - 3810

\section{أيلول - سبتمبر 2019}

العدد (43)

يتضح من جدول (3) أن 183 من أفراد عينة البحث أمهات بنسبة 45.8\%، بليهم 141 من أفراد عينة البحث

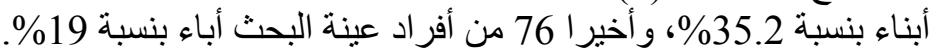

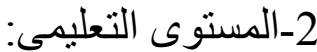

جدول (4) توزيع أفراد عينة البحث تبعا لمتغير المستوى التعليمي

\begin{tabular}{|c|c|c|}
\hline النسبة\%\% & 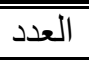 & المستوى التعليمي \\
\hline$\% 22.8$ & 91 & الثهادة الثانوية فأقلّل \\
\hline$\% 26.3$ & 105 & دبلوم \\
\hline$\% 51$ & 204 & الثشهادة الجامعية / ماجستير، دكتور اه \\
\hline$\% 100$ & 400 & المجموع \\
\hline
\end{tabular}

يتضح من جدول (4) أن 204 من أفراد عينة البحث حاصلين على الثهادة الجامعية / ماجستير، دكتوراه

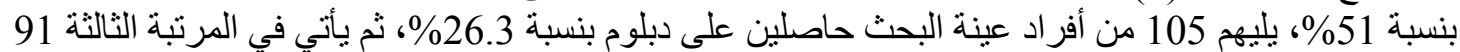

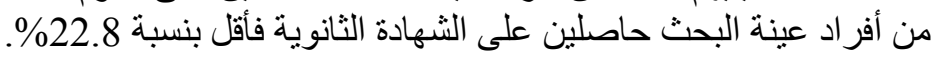

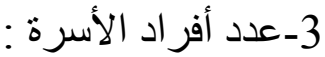

جدول (5) توزيع أسر عبنة البحث تبعاً لعدد أفرادها

\begin{tabular}{|c|c|c|}
\hline النسبة\%\% & 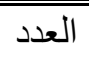 & عدد أفر اد الأسرة \\
\hline$\% 35.5$ & 142 & أقلّ من 5 أفر اد \\
\hline$\% 44.3$ & 177 & من 5 أفر اد لأقلَ من 7 أفر اد \\
\hline$\% 20.2$ & 81 & من 7 أفراد فأكثر \\
\hline$\% 100$ & 400 & المجموع \\
\hline
\end{tabular}

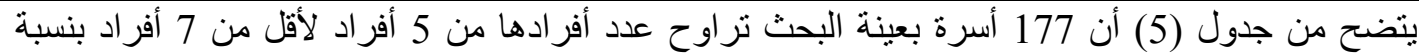

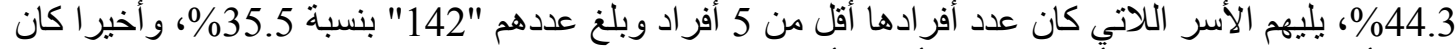
عدد الأسر اللاتي كان عدد أفر ادها من 7 أفراد فأكثر "81" الأنس أنسبة 20.2\%

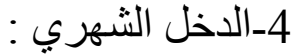

جدول (6) توزيع أفراد عينة البحث وفقا لفئات الدخل المختلفة

\begin{tabular}{|c|c|c|}
\hline 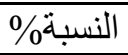 & العدد & الدخل الشهري \\
\hline$\overline{\%} 18.5$ & $\overline{74}$ & من 3000 ريال إلى اقل من 8000 ريال \\
\hline$\% 38.3$ & 153 & من 8000 ربال إلى اقل من 13000 ربيال \\
\hline$\% 27.5$ & 110 & من 13000 ربيال إلى اقل من 18000 ربيال \\
\hline$\% 15.7$ & 63 & من 18000 ربيال فأكثر \\
\hline$\% 100$ & 400 & المجموع \\
\hline
\end{tabular}

يتضح من جدول (6) أن أكبر فئات الدخل الشهري لأفر اد عينة البحث كان في الفئة (من 8000 ريال إلى اقل

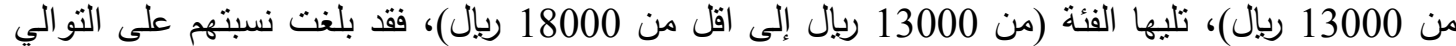

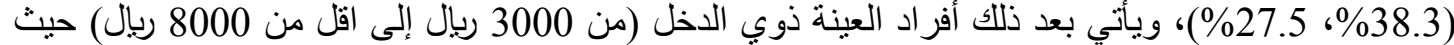

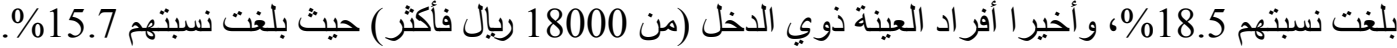




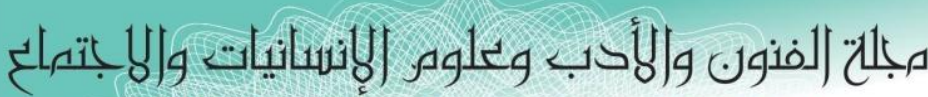
Journal of Arts, Literature, Humanities and Social Sciences

ISSN online: 2414 - 3383

ISSN print: 2616 - 3810

\section{العدد (43) ايلول - سبتهبر 2019}

تحليل النتائج وتفسير ها

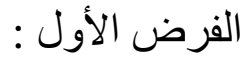

توجد فروف ذات دلالة إحصائية بين متوسط درجات أفراد العينة في الاتجاهات نحو الاستهلاك الذكي تبعا

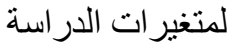

وللتحقق من هذا الفرض تم حساب تحليل التباين لدرجات أفراد العينة في الاتجاهات نحو الاستهلاك الذكي والجداول

التالية توضح ذلك :

جدول (7) تحليل التباين لدرجات أفر اد العينة في الاتجاهات نحو الاستهلاك الذكي تبعا لمتغير الجنس

\begin{tabular}{|c|c|c|c|c|c|}
\hline الدلالة & قيمة (ف) & درجات & متوسط المربعات & مجموع المربعات & الجنس \\
\hline \multirow{2}{*}{0.01 دال } & \multirow{2}{*}{39.089} & 2 & 3064.858 & 6129.715 & بين المجمو عات \\
\hline & & 397 & 78.408 & 31127.998 & داخل المجمو عات \\
\hline & & 399 & & 37257.713 & المجموع \\
\hline
\end{tabular}

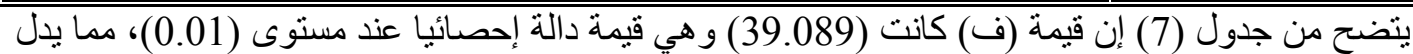

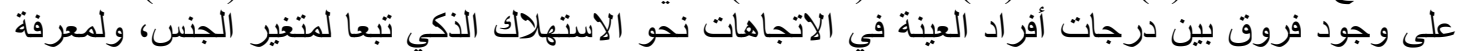

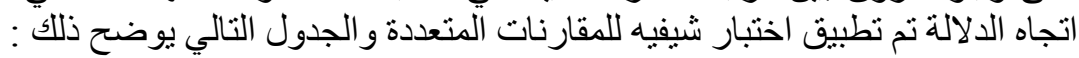
جدول (8) اختبار شيفيه للمقارنات المتعددة ولئ

\begin{tabular}{|c|c|c|c|}
\hline 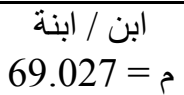 & م & م & الجنس \\
\hline & & - & أب \\
\hline & - & $* * 16.678$ & أم \\
\hline- & $* 2.536$ & $* * 19.214$ & ابن / ابنة \\
\hline
\end{tabular}

يتضح من جدول (8) وشكل (رقم7) وجود فروق في الاتجاهات نحو الاستهلاك الذكي بين الاباء وكلا من الأناء

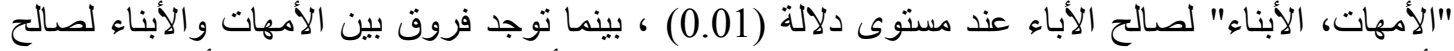

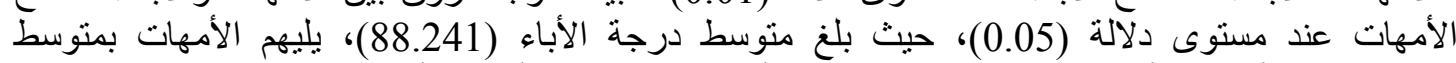

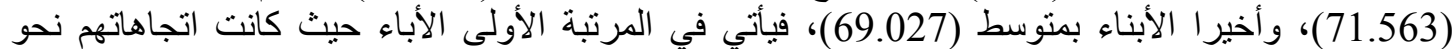

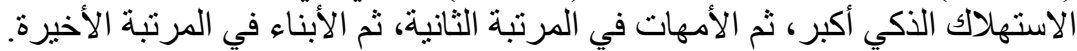

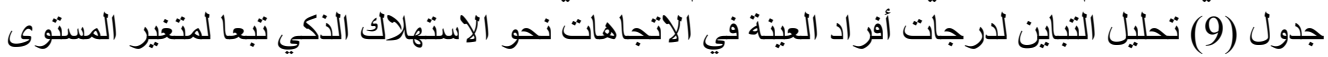
التعلبمي الاني

\begin{tabular}{|c|c|c|c|c|c|}
\hline الدلالة الد & قيمة (ف) & الحرجية & متوسط المربعات & مجموع المربعات & المستوى التعليمي \\
\hline \multirow{3}{*}{0.01} & \multirow{2}{*}{52.852} & 2 & 3193.025 & 6386.050 & بين المجمو عات \\
\hline & & 397 & 60.415 & 23984.757 & داخل المجمو عات \\
\hline & & 399 & & 30370.807 & الهجموع \\
\hline
\end{tabular}

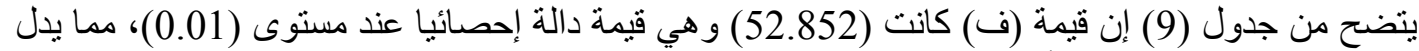

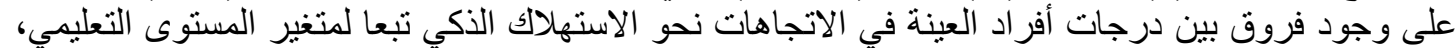

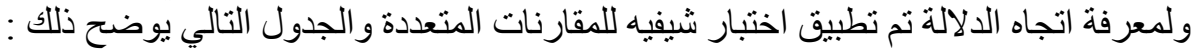




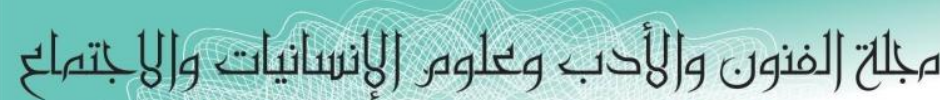
Journal of Arts, Literature, Humanities and Social Sciences

ISSN online: 2414 - 3383

ISSN print: 2616 - 3810

\section{العدد (43) ايلول - سبتمبر 2019}

جدول (10) اختبار شيفيه للمقارنات المتعددة

\begin{tabular}{|c|c|c|c|}
\hline الثهادة الجامعية / & م = & 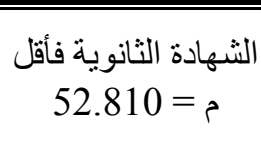 & المستوى التعليمي \\
\hline & & - & الثـهادة الثانوبة فأقل \\
\hline & - & $* * 23.211$ & دبلوم \\
\hline- & $* * 8.435$ & $* * 31.646$ & الثهادة الجامعية / ماجستير ، دكتوره \\
\hline
\end{tabular}

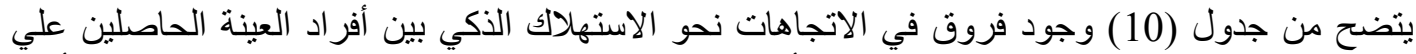

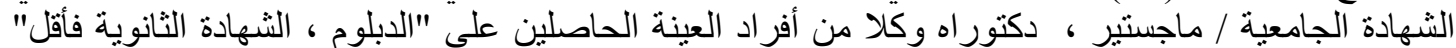

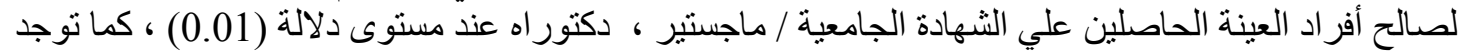

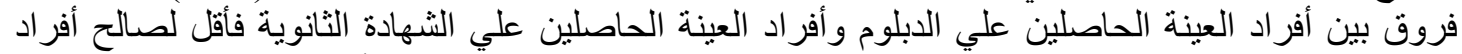

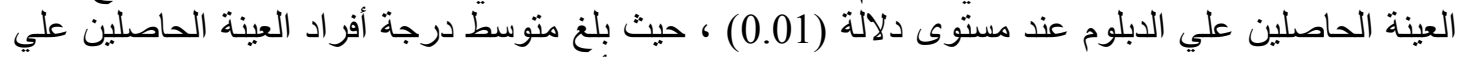

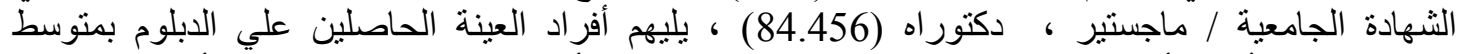

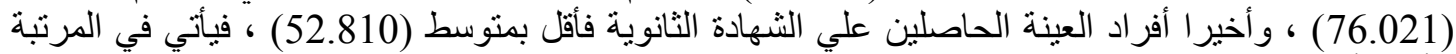

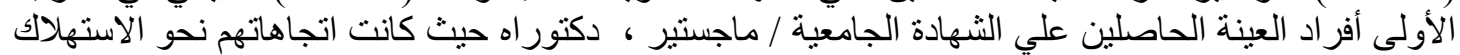
الذكي أكبر ، ثم أفراد العينة الحاصلين علي الدبلوم في المرتبة الثانية ، ثم أفراد العينة الحاصلين علي الثهادة الثادية الثانوية فأقل في المرنبة الأخيرة . جدول (11) تحليل التباين لدرجات أفراد العينة في الاتجاهات نحو الاستهلاك الذكي تبعا لمتغير عدد أفر اد الأسرة الاته

\begin{tabular}{|c|c|c|c|c|c|}
\hline الدلالة ل & قيمة (ف) & الحرجية & متوسط المربعات & مجموع المربعات & عدد أفر اد الأسرة \\
\hline \multirow{3}{*}{ دال 0.01} & \multirow{2}{*}{46.988} & 2 & 3144.260 & 6288.521 & بين المجمو عات \\
\hline & & 397 & 66.916 & 26565.839 & داخل المجمو عات \\
\hline & & 399 & & 32854.360 & المجموع \\
\hline
\end{tabular}

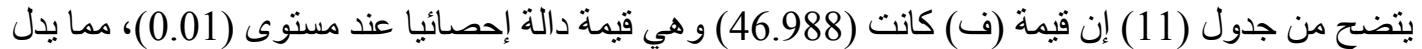

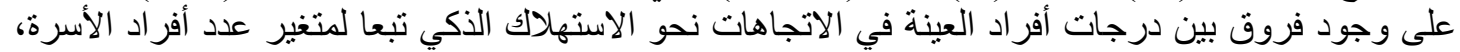

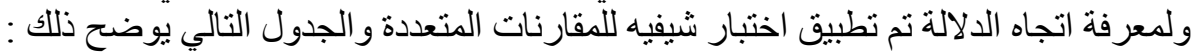
جدول (12) اختبار شيفيه للمقارنات المتعددة

\begin{tabular}{|c|c|c|c|}
\hline من 7 أفر اد فأكثر & من 5 أفر اد لأقلّ من 7 أفراد 61.223 م 61.23 & أق = من 5 أفر اد 77.792 أقل & عدد أفر اد الأسرة \\
\hline & & - & أقل من 5 أفر اد \\
\hline & - & $* * 16.569$ & من 5 أفر اد لأقلّل من 7 أفر اد \\
\hline- & $* * 13.186$ & $* * 29.755$ & من 7 أفر اد فأكثر \\
\hline
\end{tabular}

يتضح من جدول (12) وجود فروق في الاتجاهات نحو الاستهلاك الذكي بين أفراد العينة بالأسر أقل من 5 أفراد ألاد وكلا

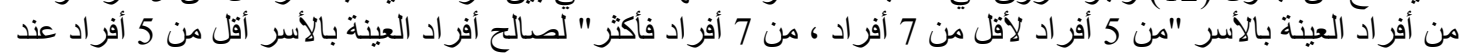

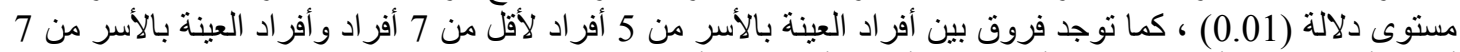

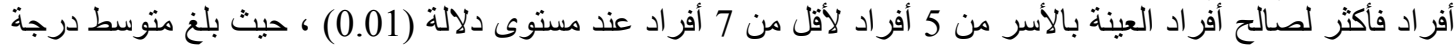
أفراد العينة بالأسر أقل من 5 أفراد (77.792) ، يليهم أفراد العينة بالأسر من 5 أفراد لألألقل من 7 أفراد بمنوسط 


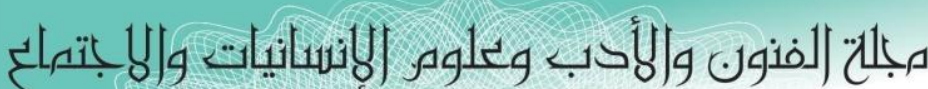

Journal of Arts, Literature, Humanities and Social Sciences

ISSN online: 2414 - 3383

ISSN print: 2616 - 3810

\section{أيلول - سبتهبر 2019}

العدد (43)

HALHSS

www.jalhss.com

(61.223) ، وأخيرا أفر اد العينة بالأسر من 7 أفراد فأكثر بمتوسط (48.037) ، فيأتي في المرتبة الأولى أفراد العبنة

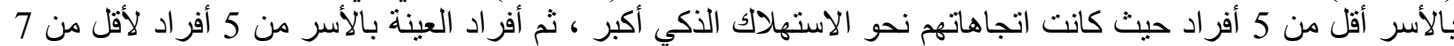

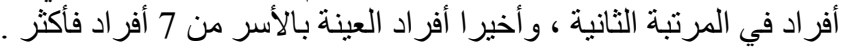

جدول (13) تحليل التباين لدرجات أفر اد العينة في الاتجاهات نحو الاستهلاك الذكي تبعا لمتغير الاخل الثهري

\begin{tabular}{|c|c|c|c|c|c|}
\hline الدلالة ل & قيمة (ف) & الحرية & متوسط المربعات & مجموع المربعات & الدخل الثهري \\
\hline \multirow{3}{*}{ دال 0.01} & \multirow{2}{*}{65.131} & 2 & 3275.864 & 6551.727 & بين المجمو عات \\
\hline & & 397 & 50.296 & 19967.685 & داخل المجمو عات \\
\hline & & 399 & & 26519.412 & المجموع \\
\hline
\end{tabular}

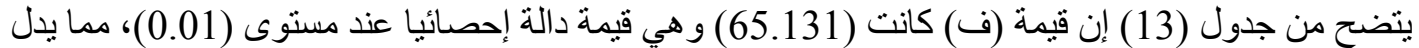

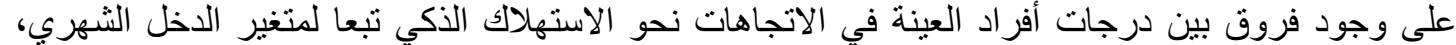

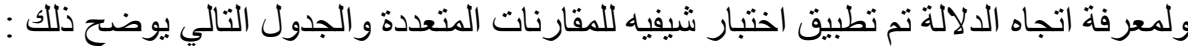
جدول (14) اختبار شيفيه للمقارنات المتعددة المدار

\begin{tabular}{|c|c|c|c|}
\hline م = مرتفع & 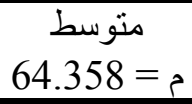 & من = منفض & الدخل الثهري \\
\hline & & - & منخفض \\
\hline & - & $* * 13.831$ & متوسط \\
\hline - & $* * 16.778$ & $* * 30.609$ & مرتفع \\
\hline
\end{tabular}

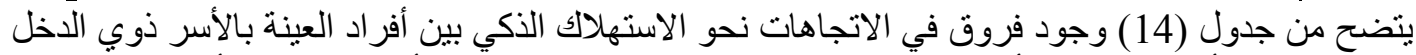

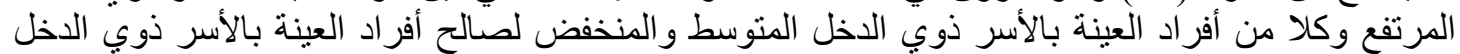

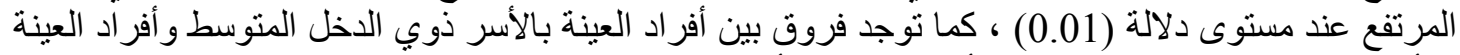

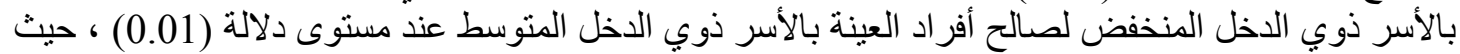

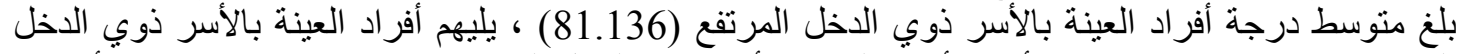

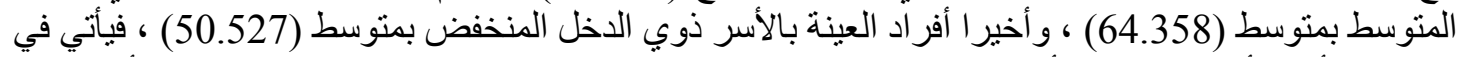

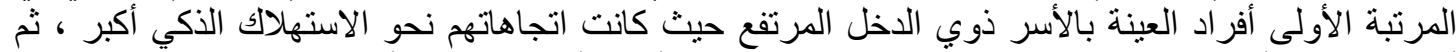

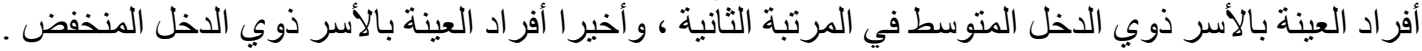

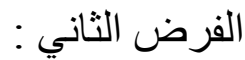

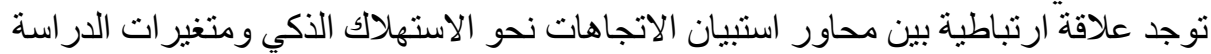

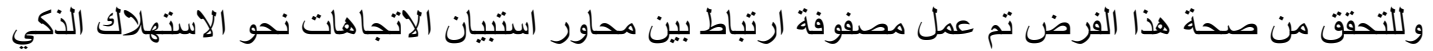

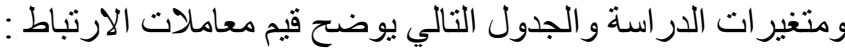

جدول (15) مصفوفة الارتباط بين محاور استبيان الاتجاهات نحو الاستهلاك الذكي ومتغيرات الألاتراسة

\begin{tabular}{|c|c|c|c|c|}
\hline الاستهاهات الذكي نحو ككل & الوجداني & المكون السلوكي & المكون المعرفي & \\
\hline 0.181 & 0.157 & 0.123 & 0.194 & الجنس \\
\hline$* * 0.883$ & $* * 0.905$ & *0.606 & $* * 0.751$ & المستوى التعليمي \\
\hline 0.145 & 0.208 & 0.171 & 0.105 & عدد أفر اد الأسرة \\
\hline$* * 0.764$ & $* 0.629$ & $* * 0.792$ & $* * 0.836$ & الدخل الثهري \\
\hline
\end{tabular}


مبلح" (لفنون والأدب وعلوه الإنسانيات والهبتهماع

Journal of Arts, Literature, Humanities and Social Sciences

ISSN online: 2414 - 3383

ISSN print: 2616 - 3810

\section{ايلول - سبتهبر 2019}

العدد (43)

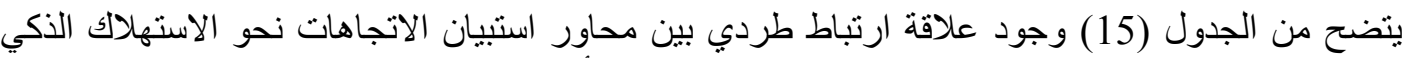

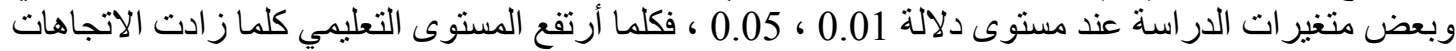

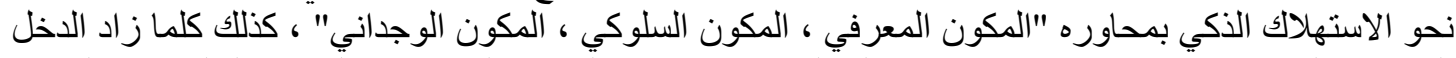

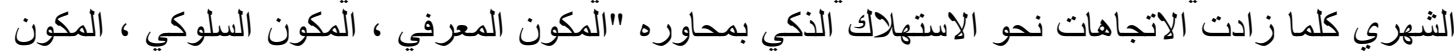

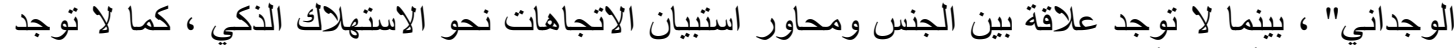

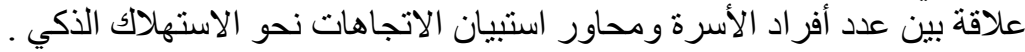

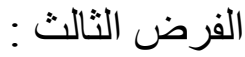

تختلف نسبة مشاركة العوامل المؤثرة على الاتجاهات نحو الاستهلاك الذكي

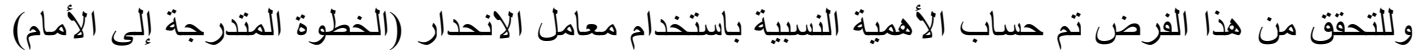

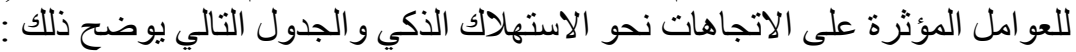

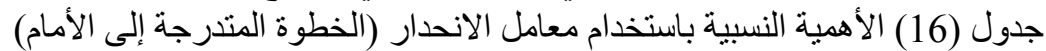
اللعو امل المؤثرة على الاتجاهات نحو الاستهلالك الذكى (لأني

\begin{tabular}{|c|c|c|c|c|c|c|c|c|}
\hline الدلالة الد & قيمة (ت) & الانحدار & الدلالة & قيمة (ف) & المشباركة & الارتباط & المتغير المستقل & \multirow{5}{*}{ 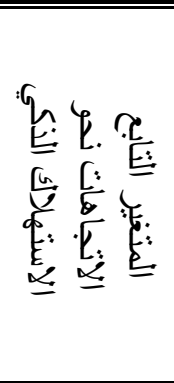 } \\
\hline 0.01 & 11.299 & 0.535 & 0.01 & 127.662 & 0.820 & 0.906 & المستوى التعليمي & \\
\hline 0.01 & 9.317 & 0.437 & 0.01 & 86.809 & 0.756 & 0.870 & الجنس الجس & \\
\hline 0.01 & 8.158 & 0.364 & 0.01 & 66.514 & 0.704 & 0.839 & الدخل الثهري & \\
\hline 0.01 & 7.483 & 0.316 & 0.01 & 55.994 & 0.667 & 0.816 & عدد أفر اد الأسرة & \\
\hline
\end{tabular}

يتضح من الجدول السابق إن المستوى التعليمي كان من أكثر العو امل المؤثرة على الاتجاهات نحو الاستهلاك

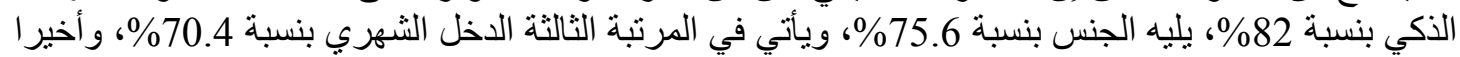

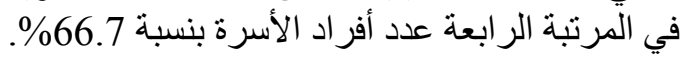

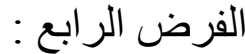

تختلف الأوزان النسبية لأولوية محاور الاتجاهات نحو الاستهلاك الذكي و للتحقق من هذا الفرض تم إعداد جدول الوزن النان النسبي التالي : جدول (17) الوزن النسبي لأولوية محاور الاتجاهات نحو الاستههلاك الذكي

\begin{tabular}{|c|c|c|c|}
\hline 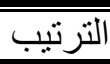 & النسبة المئوية\%\% & الوزن النببي & الاتجاهات نحو الاستهلالك الذكي \\
\hline الثاني & $\% 33.4$ & 463 & المكون المعرفي \\
\hline الأوز & $\% 36.4$ & 504 & المكون السلوكي \\
\hline الثالث & $\% 30.2$ & 418 & المكون الوجداني \\
\hline & $\overline{\%} \% 100$ & 1385 & المجموع \\
\hline
\end{tabular}

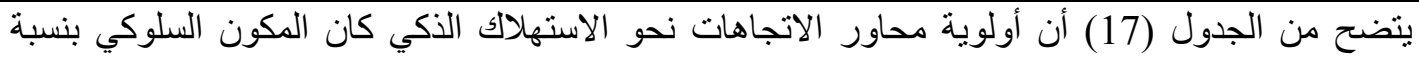

36.4\%، يليه في المرتبة الثانية المكون المعرفي بنسبة 33.4\%؛ يليه في المرتبة الثالثة المكون الوجداني بنسبة الكية $\% 30.2$ توصيات البحث : 1- نشر ثقافة الاستهلاك الذكي بين الأسر وزيادة وعيهم حول هذا الأمر ، مع مراعاة استخدام لغة مبسطة

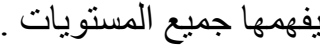
2- الاهنمام بتوعية الأسرة السعودية نحو الاستهلاك الذكي وما يحققه من فو ائد جمّة سواءً أكانت فو ائد اقتصاديّة أم مجنمعية 


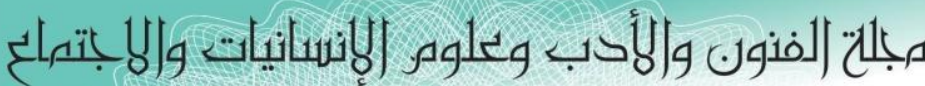

Journal of Arts, Literature, Humanities and Social Sciences

ISSN online: 2414 - 3383

ISSN print: 2616 - 3810

\section{العدد (43) ايلول - سبتمبر 2019}

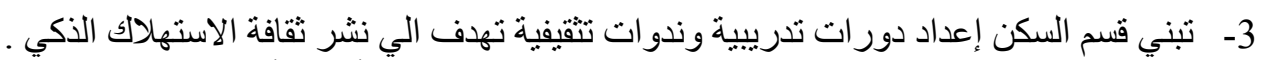

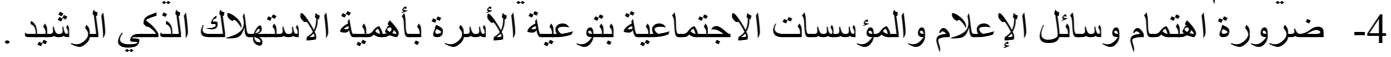

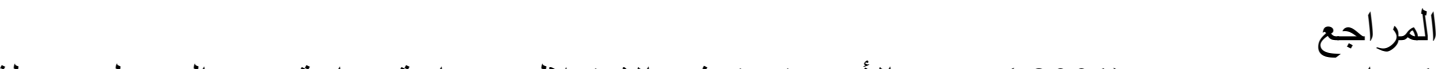

1- الحمد حسن حسين (2001م) : دور الأسرة في ترشيد الاستهلاك ، دراسة ميدانية مدين الموصل ، مجلة

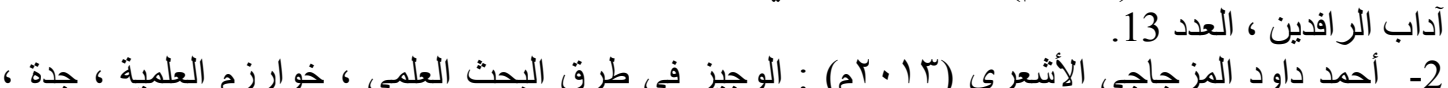

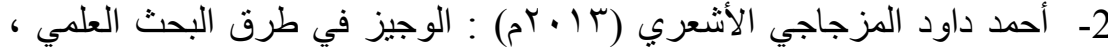

الطبعة الثانية.

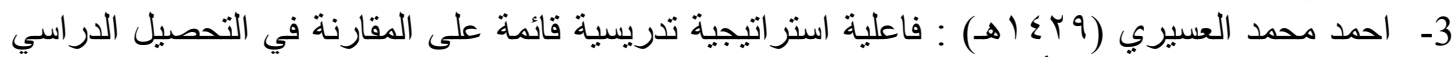

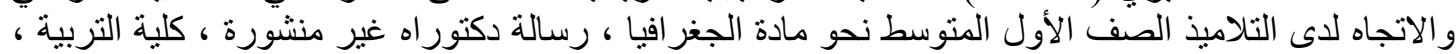

جامعة أم القرى ، مكة التلادئ المكرمة.

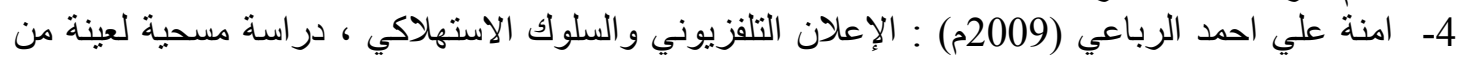

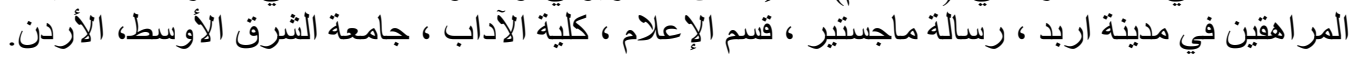

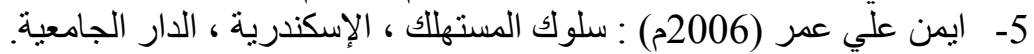

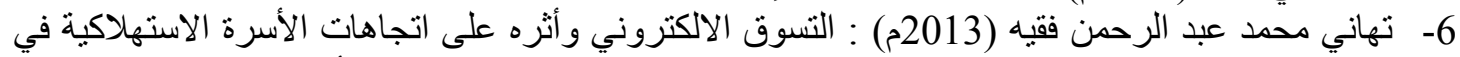

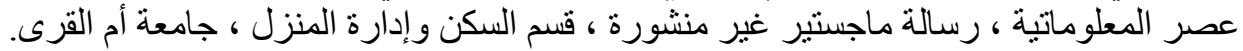

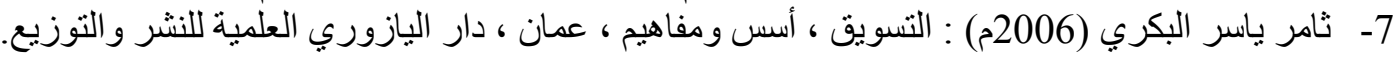

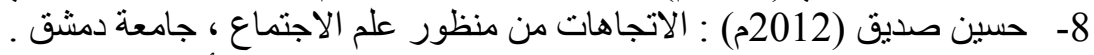

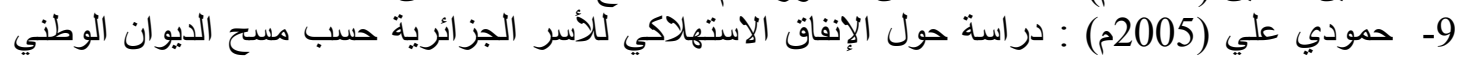

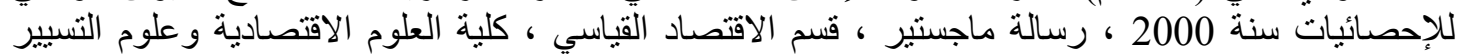

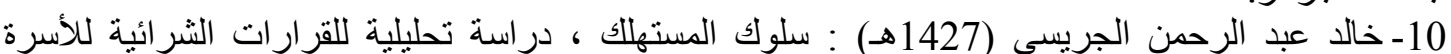

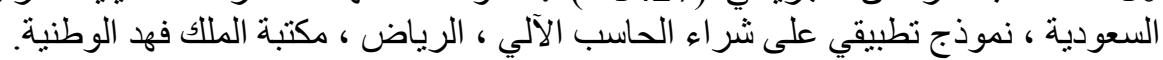

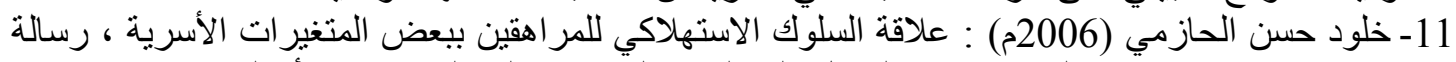

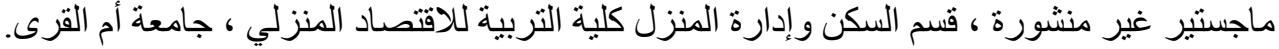

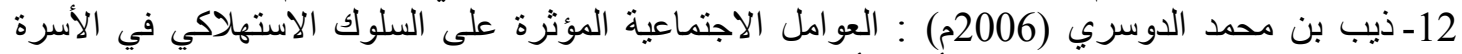

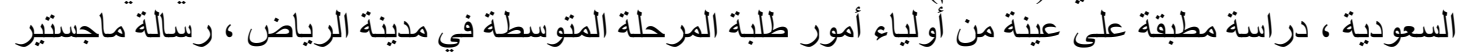

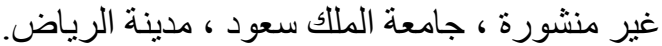

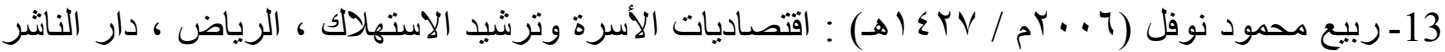

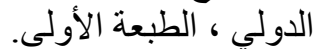
14-زيد بن محمد الرماني (2004م) : سلوك المستهلك السعودي في مجال الثراء ، إدارة البحوث بمجلس الغرف التجارية الصناعية السعودية.

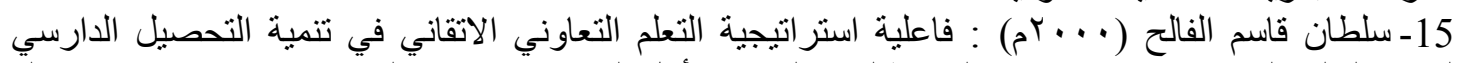

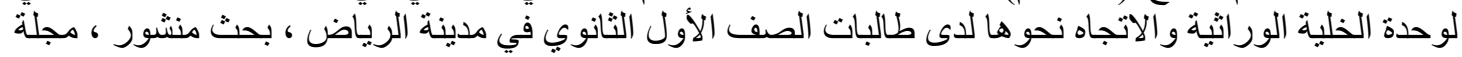

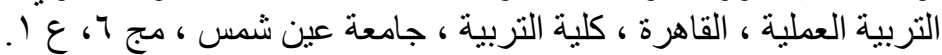
16- شهباء خزعل ذياب (2013م) : ثقافة استهلاك الملابس بين الترشيد و التبن التبديد ، كلية التربية للبنات ، جامعة

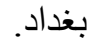

17- طارق طه (2006م) : التسويق بالانترنت والتجارة الالكترونية ، الإسكندرية ، دار الفكر الجامعي.

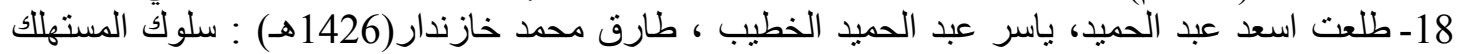

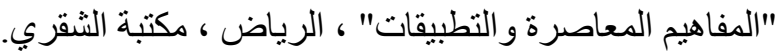

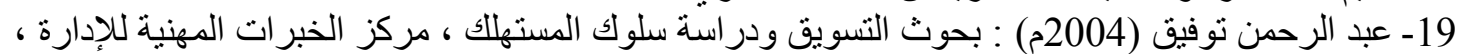

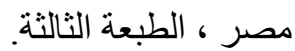

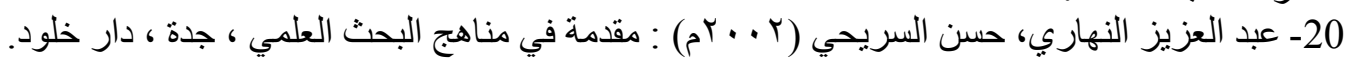




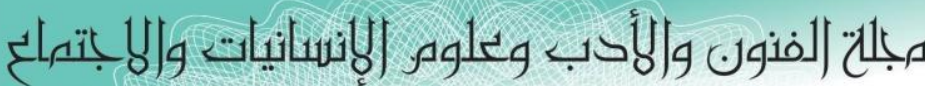

Journal of Arts, Literature, Humanities and Social Sciences

ISSN online: 2414 - 3383

ISSN print: 2616 - 3810

\section{العدد (43) ايلول - سبتمبر 2019}

21- عبد الناصر جرادات (9 . . بم) : تكنولوجيا معلومات الإعلان و أثر ها على و لاء المستهلاك للمنتج ، مجلة

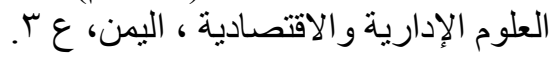

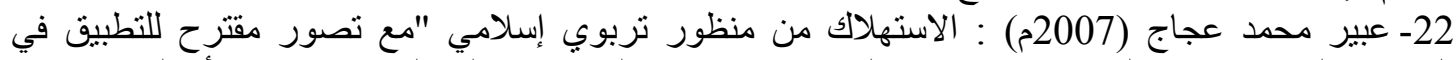

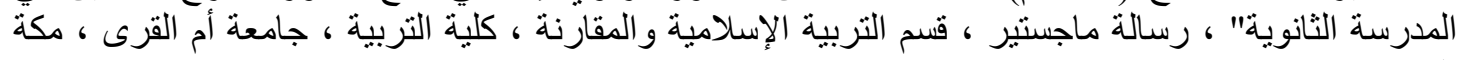

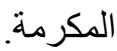

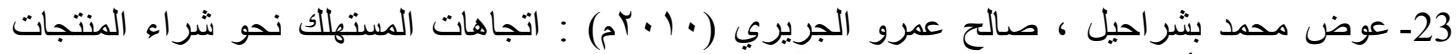

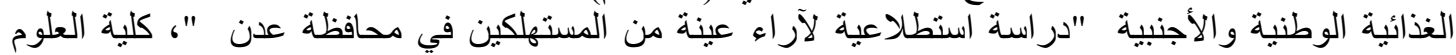

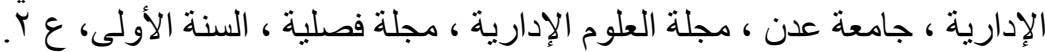

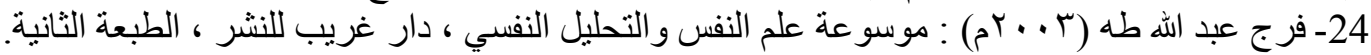

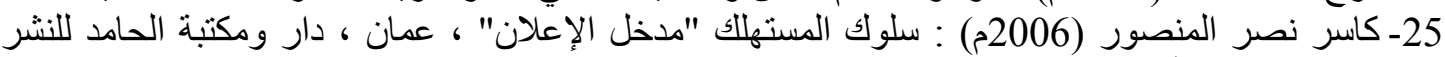

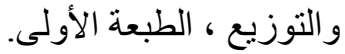

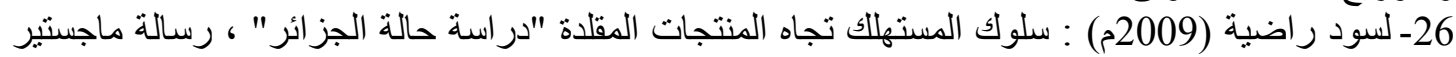

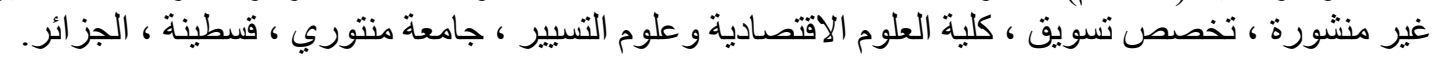

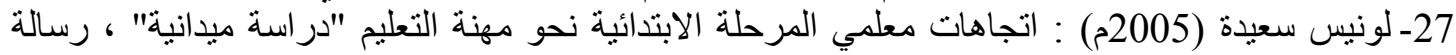

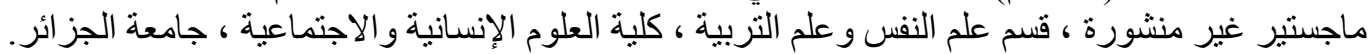

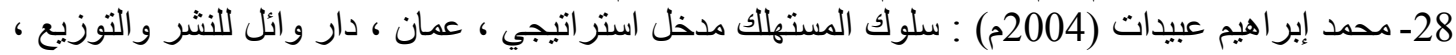

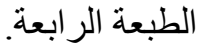

29- محمد سعيد سلطان (2003م) : السلوك التنظيمي ، الإسكندرية ، دار الجامعة الجديدة.

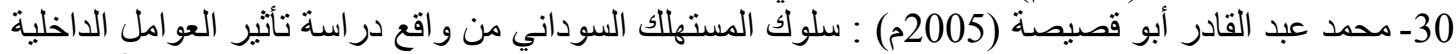

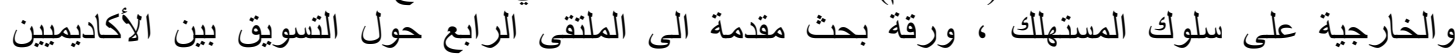

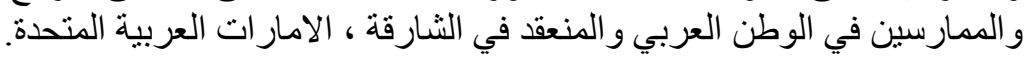

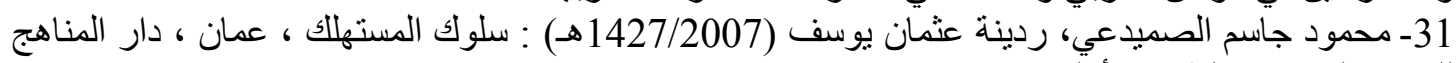
للنشر و التوزيع ، الطبعة الأولّى.

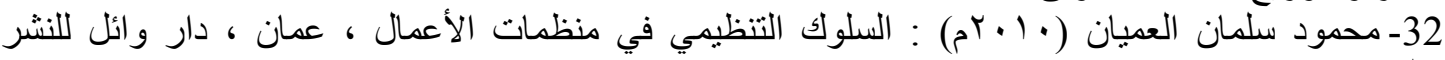
و التوزيع.

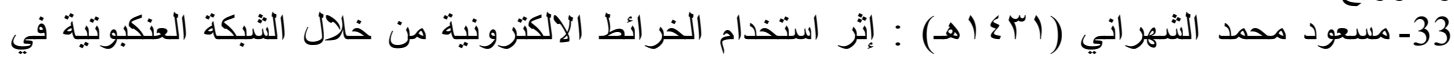

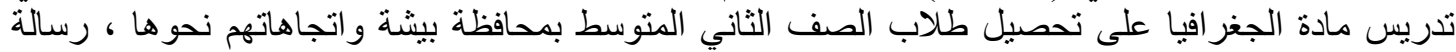

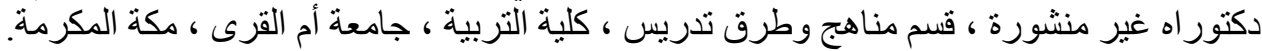

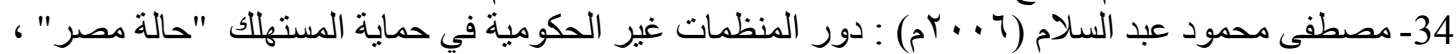

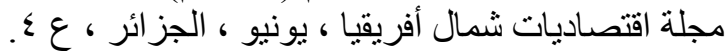

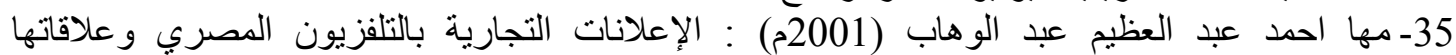

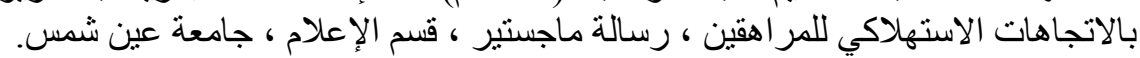

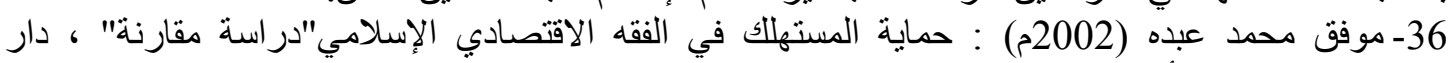

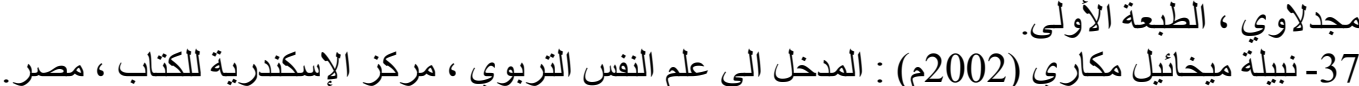

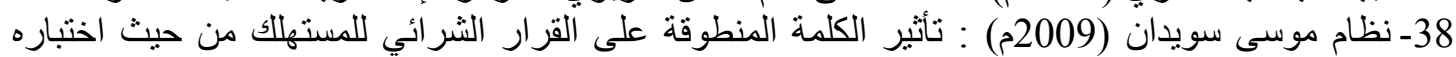

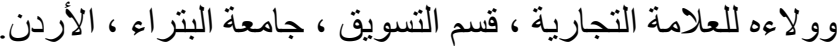

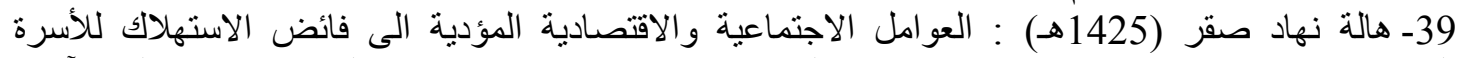

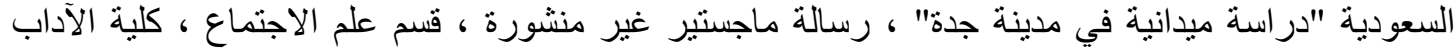
و العلوم الإنسانية ، جامعة الملك عبد العزيز. 


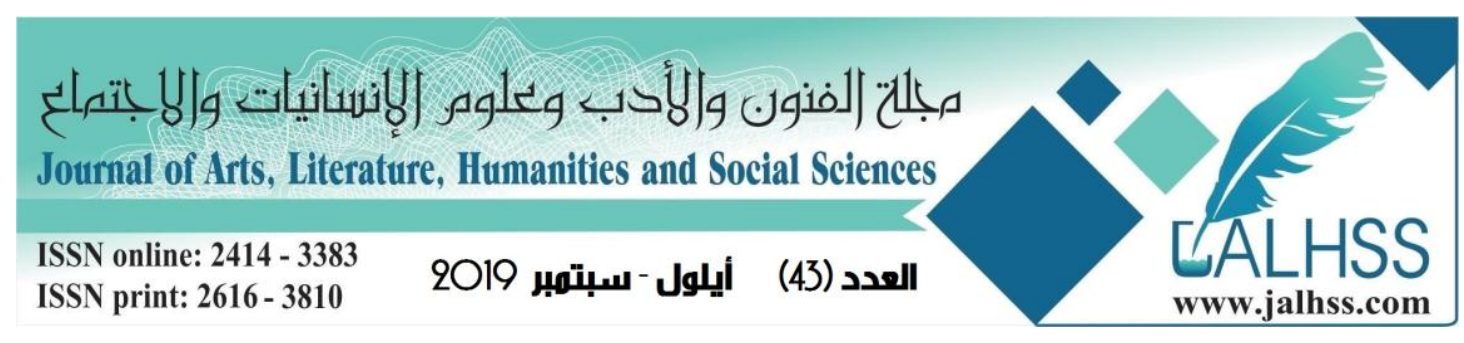

\section{References}

1- Ahmed Hassan Hussein (2001): the role of the family in the rationalization of consumption, a field study of the city of Mosul, Journal of Arts of Mesopotamia, No. 13.

2- Ahmad Dawood Al-Mazaji Al-Ash'ari (2013): A Brief in the Methods of Scientific Research, Al-Khwarizm Scientific, Jeddah, Second Edition.

3- Ahmed Mohammed Al-Asiri (1429): the effectiveness of teaching strategy based on comparison in academic achievement and the trend of first grade students towards geography, unpublished doctoral thesis, Faculty of Education, Umm Al-Qura University, Mecca.

4- 4Amna Ali Ahmed Rubai (2009): TV advertising and consumer behavior, a survey study of a sample of adolescents in the city of Irbid, Master Thesis, Department of Media, Faculty of Arts, Middle East University, Jordan.

5- Ayman Ali Omar (2006): Consumer Behavior, Alexandria, University House.

6- Tahani Mohammed Abdul Rahman Fakih (2013): e-shopping and its impact on consumer trends in the information age, an unpublished Master Thesis, Department of Housing and Home Management, Umm Al-Qura University.

7- Thamer Yasser Al-Bakri (2006): Marketing, Foundations and Concepts, Amman, Dar Al Yazouri Scientific Publishing and Distribution.

8- Hussein Seddiq (2012): Trends from the Sociological Perspective, Damascus University.

9- Hamoudi Ali (2005): A study on the consumption expenditure of Algerian families according to the National Bureau of Statistics Survey in 2000, Master Thesis, Department of Econometrics, Faculty of Economic Sciences and Management Sciences University of Algeria.

10- Khalid Abdulrahman Al-Jeraisy (1427H): Consumer Behavior, An Analytical Study of the Purchasing Decisions of the Saudi Family, An Application Model on Computer Purchase, Riyadh, King Fahd National Library.

11- Kholoud Hassan Al-Hazmi (2006): The relationship between the consumption behavior of adolescents with some family variables, unpublished Master Thesis, Department of Housing and Home Management College of Education for Home Economics, Umm Al-Qura University.

12- Theeb bin Mohammed Al-Dosari (2006): Social Factors Affecting Consumer Behavior in the Saudi Family, A Study Applied to a Sample of Parents of Middle School Students in Riyadh City, Unpublished Master Thesis, King Saud University, Riyadh City.

13- Rabie Mahmoud Nofal (2006 / 1427H): Family Economics and Rationalization of Consumption, Riyadh, International Publisher House, First Edition.

14- Zaid bin Mohammed Al-Ramani (2004): Saudi consumer behavior in the field of procurement, Research Department, Council of Saudi Chambers of Commerce and Industry. 


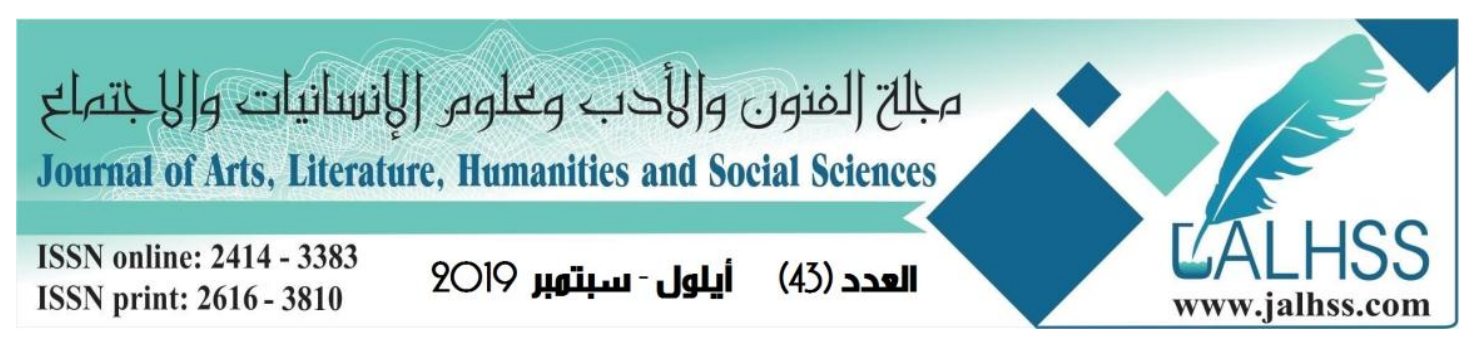

15-Sultan Qassim Al-Faleh (2000): The Effectiveness of the Cooperative Learning Strategy in Developing the Academic Achievement of the Genetic Cell Unit and its Attitude towards the First Year Secondary School Students in Riyadh City, Published Research, Journal of Practical Education, Cairo, Faculty of Education, Ain Shams University, vol. 6. 1.

16- Shahba Khazaal Dhiab (2013): a culture of clothing consumption between rationalization and waste, College of Education for Girls, University of Baghdad.

17- Tarek Taha (2006): Internet Marketing and Electronic Commerce, Alexandria, Dar Al-Fikr Al-Jama'i.

18- Talaat Asaad Abdul Hamid, Yasser Abdul Hamid Al-Khatib, Tariq Mohammed Khazindar (1426 e): consumer behavior "contemporary concepts and applications", Riyadh, Al-Shukri Library.

19- Abdel Rahman Tawfik (2004): Marketing Research and Consumer Behavior Study, Center of Professional Experience of Management, Egypt, Third Edition.

20- Abdul Aziz Al-Nahari, Hassan Al-Suraihi (2002): Introduction to Scientific Research Methods, Jeddah, Dar Kholoud.

21- Abdul Nasser Jaradat (2009): Information Technology and its impact on consumer loyalty to the product, Journal of Administrative and Economic Sciences, Yemen, p 3.

22- Abeer Mohammed Ajaj (2007): Consumption from an Islamic Educational Perspective "with a Proposed Concept for Application in Secondary School", Master Thesis, Department of Islamic and Comparative Education, College of Education, Umm Al-Qura University, Makkah.

23- Awad Mohammed Bashrahil, Saleh Amr Al-Jariri (2010): Consumer Attitudes Towards the Purchase of National and Foreign Food Products, "An Exploratory Study of the Opinions of a Sample of Consumers in the Governorate of Aden", Faculty of Administrative Sciences, University of Aden, Journal of Administrative Sciences, Quarterly Magazine, First Year P 2.

24- Faraj Abdullah Taha (2003): Encyclopedia of Psychology and Psychoanalysis, Dar Gharib for Publishing, 2nd Edition.

25- Kasir Nasr Al-Mansour (2006): Consumer Behavior "Advertising Entrance", Amman, Al-Hamed Library and Publishing, First Edition.

26- Lassad Radhia (2009): Consumer Behavior Towards Counterfeit Products, "Case Study of Algeria", Unpublished Master Thesis, Marketing Major, Faculty of Economic and Management Sciences, University of Mentouri, Constantine, Algeria.

27- Lounis Saida (2005): Attitudes of Elementary Teachers towards the Teaching Profession "Field Study", Unpublished Master Thesis, Department of Psychology and Education, Faculty of Humanities and Social Sciences, University of Algeria. 


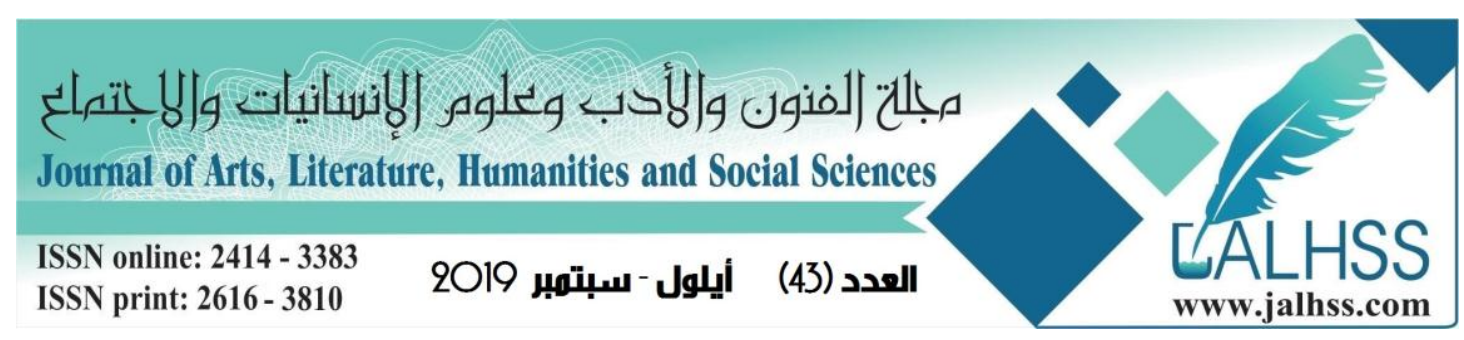

28- Mohammed Ibrahim Obeidat (2004): Consumer Behavior Strategic Approach, Amman, Wael Publishing and Distribution House, Fourth Edition.

29- Mohamed Said Sultan (2003): Organizational Behavior, Alexandria, New University House.

30- Mohammed Abdul Qader Abu Qusaisah (2005): Sudanese consumer behavior from the reality of the study of the impact of internal and external factors on consumer behavior, a paper presented to the fourth forum on marketing between academics and practitioners in the Arab world, held in Sharjah, United Arab Emirates.

31- Mahmoud Jassim Al-Sumaida'i, Rudaina Othman Yousef (2007 / 1427H): Consumer Behavior, Amman, Dar Al-Manahej for Publishing and Distribution, First Edition

32- Mahmoud Salman Al-Omayyan (2010): Organizational Behavior in Business Organizations, Amman, Wael Publishing and Distribution.

33-Massoud Mohammed Al-Shahrani (1431H): The use of electronic maps through the Internet in teaching geography on the achievement of second grade students in Bisha governorate and their attitudes towards it, unpublished doctoral dissertation, Department of Curriculum and Teaching Methods, Faculty of Education, Umm Al-Qura University, Mecca Al Mukarramah.

34- Mustafa Mahmoud Abdel Salam (2006): The Role of NGOs in Consumer Protection, "The Case of Egypt", Journal of North African Economies, June, Algeria, p.4.

35- Maha Ahmed Abdel Azim Abdel Wahab (2001): commercials in Egyptian television and its relations with the consumption trends of adolescents, Master Thesis, Department of Media, Ain Shams University.

36- Mowaffaq Mohammed Abdo (2002): Consumer Protection in Islamic Economic Jurisprudence "A Comparative Study", Dar Majdalawi, First Edition.

37- Nabila Michael Makari (2002): Introduction to Educational Psychology, Alexandria Book Center, Egypt.

38- Musa Sweidan System (2009): The Effect of Spoken Word on Consumer Purchasing Decision in Test and Brand Loyalty, Marketing Department, Petra University, Jordan.

39- Hala Nihad Sakr (1425H): Socio-economic Factors Leading to Surplus Consumption of the Saudi Family, "An Empirical Study in Jeddah City", Unpublished Master Thesis, Department of Sociology, Faculty of Arts and Humanities, King Abdulaziz University.

40-Catherine viot, (2006): Influencing the Online Consumer's Behavior: THE Web Experience. Internet Research MCB university press, vo1, 14, no.2.

41- Denis Darpy et p. volle (2003): comportement du consommateur concept et outil, dunod, paris

42- Philip.Kotler, DUBOIS: (2006): Marketing management, 12 editionm pearson education, Paris. 